\title{
A POLICY MAKER'S GUIDE TO DESIGNING PAYMENTS FOR ECOSYSTEM SERVICES
}

\author{
James Salzman \\ Samuel F. Mordecai Professor of Law \\ Nicholas Institute Professor of Environmental Policy \\ Duke University \\ United States
}




\section{TABLE OF CONTENTS}

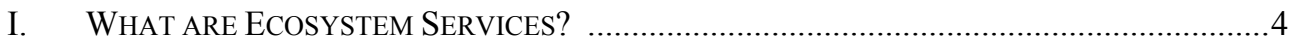

A. What is the State of Ecosystem Service? .............................................................6

B. How Valuable are Ecosystem Services? ............................................................... 8

C. Why are Ecosystem Services Under-protected? .................................................10

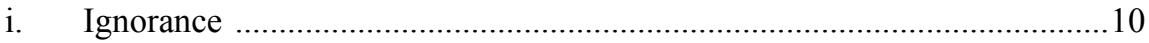

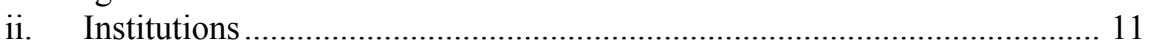

iii. Market Failures.......................................................................................... 11

D. Why choose payments over other policy instruments? .......................................12

i. Traditional environmental policy tools..................................................... 12

ii. Payments for Ecosystem Services (PES) ............................................... 15

iii. Types of Services Receiving Payments ........................................................ 19

II. DESIGNING PAYMENTS FOR ECOSYSTEM SERVICES …................................................. 20

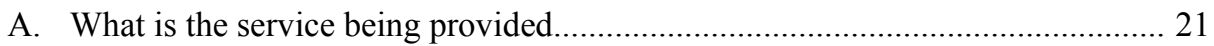

B. Who provides the service and who benefits? ..................................................... 22

i. Potential buyers .............................................................................. 24

a. Public versus private buyers ........................................................... 25

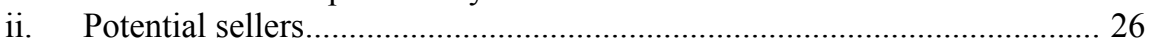

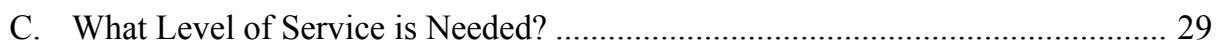

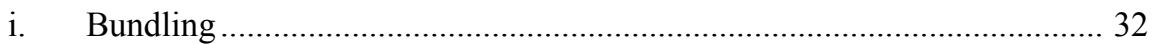

D. Service Payment Mechanisms ……………………......................................... 32

i. $\quad$ Direct Payment - General Subsidy .............................................................. 33

ii. Direct Payment - Negotiation ………………........................................34

iii. Direct Payment - Scored Subsidy …………………................................... 35

iv. Direct Payment - Reverse Auction ............................................................ 36

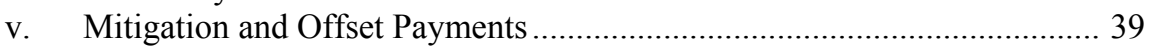

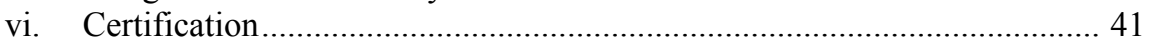

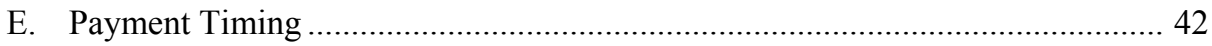

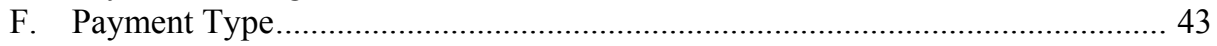

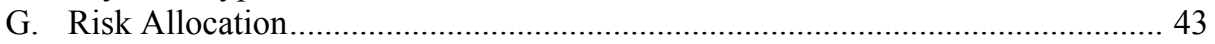

III. DESIGN CHALLENGES TO EFFECTIVE PES PROGRAMS ................................................. 44

A. Modeling and Monitoring - Can you measure what matters? ............................. 45

B. Property Rights - Does the seller control the service? …………...................... 47

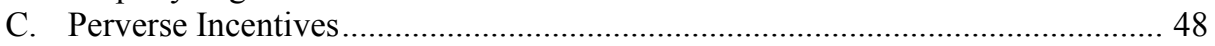

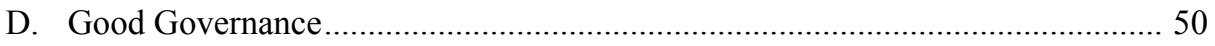

i. Public participation.......................................................................... 51

ii. Transparency and access to information.................................................... 52

iii. Accountability and the Rule of Law ........................................................ 52

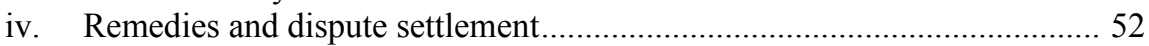

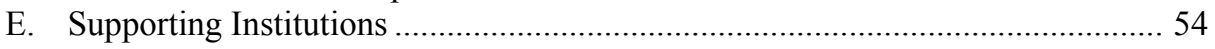

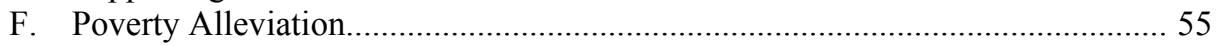

\section{BOXES and FIGURES}

Box 1: Classification of Ecosystem Services ………....................................... 5

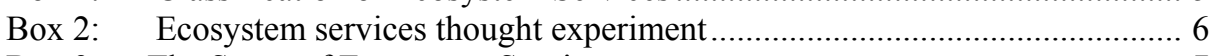

Box 3: The States of Ecosystem Services …………............................................. 7

Box 4: The Environmental Policy Toolkit .......................................................... 13

Box 5: The Environmental Policy Toolkit in a watershed ..................................... 15

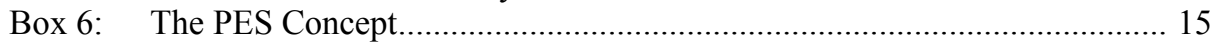

Box 7: New York City and the Catskills Watershed - Investing in

Natural Capital Instead of Built Capital ................................................. 16

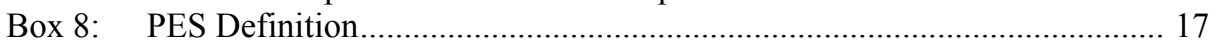

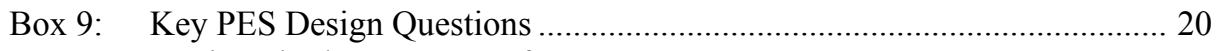

Box 10: Perrier Vittel payments to farmers.............................................................. 23 
Box 11: Payments by Energía Global for service of erosion control.......................... 27

Box 12: Payments by Macquarie River Fruit and Fibre for Evapotranspiration ....... 30

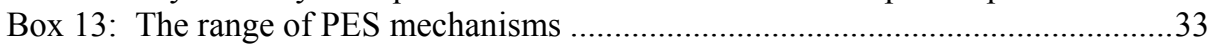

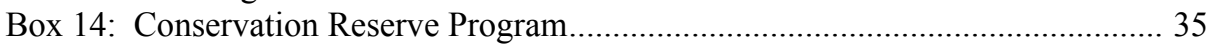

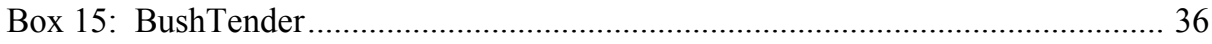

Box 16: Wetlands Mitigation Banking .................................................................. 39

Box 17: Forest Stewardship Council ...................................................................... 42

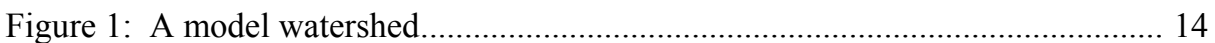

Figure 2: Distribution of service provision among farmers .................................... 30

Figure 3: Graphing Biodiversity and Habitat Scores of Field Sites........................... 38 


\section{WHAT ARE ECOSYSTEM SERVICES?}

When we go to a store, we expect to find useful goods and services - the apples we buy to eat and the refrigerators that keep them chilled. We depend on similar goods and services in our everyday lives. Indeed, we take them for granted. Nature also provides us valuable goods and services, and we take many of those for granted, as well. When we bite into a juicy apple, for example, if we pause to think beyond the store where it was purchased, we may think of soil and water; but it is unlikely we also consider the natural pollinators that fertilized the apple blossom so the fruit can set. When we drink a cool glass of water from the tap we may think of the local reservoir, but the real source of the water quality lies many miles upstream in the wooded watershed that filters and cleans the water as it flows downhill. When we enjoy a fun holiday at the beach we may think of the warm sun, but not of the carbon sequestration by plants that contributes to climate stability.

Largely taken for granted, healthy ecosystems provide a variety of such critical goods and services. Created by the interactions of living organisms with their environment, these "ecosystem services" provide both the conditions and processes that sustain human life. The importance to our well-being of goods provided by ecosystems is straightforward. Trees provide timber; coastal marshes provide shellfish. The services underpinning these goods, though less visible, are equally important. If you doubt this, consider how to grow an apple without the services of pollination, pest control or renewal of soil fertility.

A specific landscape might provide a range of ecosystem services. ${ }^{1}$ A forest at the top of a watershed, for example, can provide the service of water quality (filtering the water from contaminants as it flows through roots and soil), the service of flood control (as the water slows in moving through the watershed), the service of pollination (provided by the pollinators living along the edge of the forest), and biodiversity conservation (if endangered plants or animals live in the woods). Or consider something as simple as soil. More than a clump of dirt, soil is a complex matrix of organic and inorganic constituents transformed by numerous tiny organisms. The level of biological activity within soil is staggering. Under a square meter of pasture soil in Denmark, scientists identified over 50,000 worms, 48,000 small insects, and 10 million nematodes. This living soil provides six ecosystem services: buffering and moderation of the hydrological cycle (so precipitation may be soaked up and metered out rather than rushing off the land in flash floods), physical support for plants, retention and delivery of nutrients to plants, disposal of wastes and dead organic matter, renewal of soil fertility, and regulation of the major element cycles (Daily 1997).

\footnotetext{
${ }^{1}$ Publications on this topic sometimes use the similar terms, "environmental services" or "ecological services." For the purposes of this report, the term "ecosystem services" will be used to describe the benefits provided by ecosystems.
} 
While one can categorize ecosystem services any number of ways, the most common approach is that employed by the Millennium Ecosystem Assessment. It divided services into four categories, exhibited below in Box 1:

- provisioning services (the products obtained from ecosystems)

- regulating services (the benefits obtained from the regulation of ecosystem processes)

- cultural services (the non-material benefits that people obtain from ecosystems through spiritual enrichment, cognitive development, reflection, recreation and aesthetic experiences) that directly affect people

- supporting services needed to maintain other services.

\begin{tabular}{|c|c|c|c|c|}
\hline Services & $\begin{array}{l}\text { Provisioning } \\
\text { services }\end{array}$ & Regulating services & Cultural services & Supporting services \\
\hline $\begin{array}{c}\text { Sub- } \\
\text { category }\end{array}$ & $\begin{array}{l}\text { - food } \\
\text { - fiber } \\
\text { - genetic resources } \\
\text { - bio-chemicals, } \\
\text { natural medicines } \\
\text { and } \\
\text { pharmaceuticals } \\
\text { - } \text { ornamental } \\
\text { resources } \\
\text { - fresh water }\end{array}$ & $\begin{array}{l}\text { - } \text { air quality } \\
\text { regulation } \\
\text { - climate } \\
\text { regulation } \\
\text { - } \text { water regulation } \\
\text { - } \text { erosion } \\
\text { regulation } \\
\text { - } \text { water purification } \\
\text { and waste } \\
\text { treatment } \\
\text { - disease regulation } \\
\text { - pest regulation } \\
\text { - pollination } \\
\text { - natural hazard } \\
\text { regulation } \\
\end{array}$ & $\begin{array}{l}\text { - } \text { cultural diversity } \\
\text { - } \text { spiritual and } \\
\text { religious values } \\
\text { - } \text { knowledge } \\
\text { - } \text { systems } \\
\text { - educational } \\
\text { - } \text { values } \\
\text { - } \text { inspiration } \\
\text { - } \text { sesthetic values } \\
\text { - social relations } \\
\text { - cultural heritage } \\
\text { - } \text { values } \\
\text { recreation and } \\
\text { ecotourism } \\
\end{array}$ & $\begin{array}{l}\text { - } \text { soil formation } \\
\text { - photosynthesis } \\
\text { - primary } \\
\text { - } \text { production } \\
\text { - } \text { nutrient recycling } \\
\text { water cycling }\end{array}$ \\
\hline
\end{tabular}

Services are provided and enjoyed across a range of scales. Pollination and renewal of soil fertility are local services, while climate stabilization and genetic resources are generated locally (through carbon sequestration and biodiversity conservation) but enjoyed globally. Thus, depending on the service, a wide range of landscapes can be important service providers, from pristine, intact ecosystems such as natural forests, wetlands and estuaries, to human-dominated landscapes such as agricultural lands.

Just as we tend not to think about everyday goods and services until the store is out of apples or the lights do not work, so, too, do we generally fail to appreciate the importance of services until we suffer the impacts of their loss. One cannot easily 
appreciate the impact that widespread wetland destruction has had on the ecosystem service of water retention until after a flood. Nor does one fully appreciate water quality until recognizing how development in forested watersheds has degraded the service of water purification. Nor is the importance of vegetative cover on hill slopes often recognized until overgrazing or intensive farming increases sedimentation downstream. The costs from degradation of these services are high, and suffered in rich and poor countries alike (Landell Mills and Porras 2002).

Indeed, if one thinks about it, ecosystem services are not merely beneficial to our well-being; they are critical. The thought experiment described below by Gretchen Daily explains well the fundamental importance of ecosystem services. She asks us to imagine loading the cargo of a space ship flying to another planet with an atmosphere and climate similar to earth's (Daily 1997).

\section{Box 2: Ecosystem services thought experiment}

Tackling the problem systematically, you could first choose from among all the species exploited directly for food, drink, spice, fiber and timber, pharmaceuticals, industrial products (such as waxes, rubber, and oils), and so on. Even being selective, this list could amount to hundreds or even several thousand species. The space ship would be filling up before you'd even begun adding the species crucial to supporting those at the top of your list. Which are these unsung heroes? No one knows which - nor even approximately how many — species are required to sustain human life. This means that rather than listing species directly, you would have to list instead the life-support functions required by your lunar colony; then you could guess at the types and numbers of species required to perform each. At a bare minimum, the spaceship would have to carry species capable of supplying a whole suite of ecosystem services that earthlings take for granted. These services include:

- purification of air and water

- mitigation of floods and droughts

- detoxification and decomposition of wastes

- generation and renewal of soil and soil fertility

- pollination of crops and natural vegetation

- control of the vast majority of potential agricultural pests

- dispersal of seeds and translocation of nutrients

- maintenance of biodiversity, from which humanity has derived

key elements of its agricultural, medicinal, and industrial enterprise

- protection from the sun's harmful ultraviolet rays

- partial stabilization of climate

- moderation of temperature extremes and the force of winds and waves

- support of diverse human cultures

- providing of aesthetic beauty and intellectual stimulation that lift the human spirit

Armed with this preliminary list of services, you could begin to determine which types and numbers of species are required to perform each. This is no simple task! 


\section{A. What is the State of Ecosystem Services?}

Ecosystem services are clearly important to human well-being. We have come to enjoy, indeed, take for granted, nature's bounty. But is this confidence warranted? The Millennium Ecosystem Assessment was launched in 2001 to address this very question. The Assessment relied on the contributions of over 1,360 experts from over 95 countries around the globe to examine the consequences of ecosystem change for human wellbeing, as well as the actions needed to enhance the conservation and sustainable use of these systems. It represented the first attempt by the scientific community to assess globally the full range of benefits provided by nature. The table below summarizes their conclusions about the status of twenty-four different ecosystem goods and services, as well as their trendlines (increasing $\boldsymbol{\Lambda}$, decreasing $\boldsymbol{\nabla}$, or stable $+/-$ ) (Millennium Ecosystem Assessment 2005).

\section{Box 3: The States of Ecosystem Services}

\begin{tabular}{|c|c|c|c|}
\hline Service & Sub-category & Status & Notes \\
\hline \multicolumn{4}{|l|}{$\begin{array}{l}\text { Provisioning } \\
\text { Services } \\
\end{array}$} \\
\hline \multirow[t]{5}{*}{ Food } & crops & $\Delta$ & substantial production increase \\
\hline & livestock & $\Delta$ & substantial production increase \\
\hline & capture fisheries & $\boldsymbol{\nabla}$ & declining production due to overharvest \\
\hline & aquaculture & $\Delta$ & substantial production increase \\
\hline & wild foods & $\nabla$ & declining production \\
\hline \multirow[b]{4}{*}{ Genetic resources } & \multirow{3}{*}{$\begin{array}{l}\text { timber } \\
\text { cotton, hemp, silk } \\
\text { wood fuel }\end{array}$} & $+/$ & forest loss in some regions, growth in others \\
\hline & & $+/-$ & declining production of some fibers, growth in others \\
\hline & & $\boldsymbol{\nabla}$ & declining production \\
\hline & & $\boldsymbol{\nabla}$ & lost through extinction and crop genetic resource loss \\
\hline $\begin{array}{l}\text { Biochemicals, } \\
\text { natural medicines, } \\
\text { pharmaceuticals }\end{array}$ & & $\nabla$ & lost through extinction, overharvest \\
\hline Fresh water & & $\boldsymbol{\nabla}$ & $\begin{array}{l}\text { unsustainable use for drinking, industry, and irrigation; } \\
\text { amount of hydro energy unchanged, but dams increase } \\
\text { ability to use that energy }\end{array}$ \\
\hline \multicolumn{4}{|l|}{$\begin{array}{l}\text { Regulating } \\
\text { Services }\end{array}$} \\
\hline $\begin{array}{l}\text { Air quality } \\
\text { regulation }\end{array}$ & & $\boldsymbol{\nabla}$ & decline in ability of atmosphere to cleanse itself \\
\hline \multirow[t]{2}{*}{ Climate regulation } & global & $\boldsymbol{\Delta}$ & net source of carbon sequestration since mid-century \\
\hline & regional and local & $\boldsymbol{\nabla}$ & preponderance of negative impacts \\
\hline Water regulation & & $+/-$ & varies depending on ecosystem change and location \\
\hline Erosion regulation & & $\boldsymbol{\nabla}$ & increased soil degradation \\
\hline $\begin{array}{l}\text { Water purification } \\
\text { and }\end{array}$ & & $\boldsymbol{\nabla}$ & declining water quality \\
\hline
\end{tabular}




\begin{tabular}{|l|cl|} 
waste treatment & & \\
\hline Disease regulation & $+/-$ & varies depending on ecosystem change \\
\hline Pest regulation & $\boldsymbol{\nabla}$ & natural control degraded through pesticide use \\
\hline Pollination & $\boldsymbol{\nabla}^{\text {a }}$ & apparent global decline in abundance of pollinators \\
\hline $\begin{array}{l}\text { Natural hazard } \\
\text { regulation }\end{array}$ & $\boldsymbol{\nabla}$ & loss of natural buffers (wetlands, mangroves) \\
\hline Cultural Services & & \\
\hline $\begin{array}{l}\text { Spiritual and } \\
\text { religious values }\end{array}$ & $\boldsymbol{\nabla}$ & rapid decline in sacred groves and species \\
\hline Aesthetic values & $\boldsymbol{\nabla}$ & decline in quantity and quality of natural lands \\
\hline $\begin{array}{l}\text { Recreation and } \\
\text { ecotourism }\end{array}$ & $+/-$ & more areas accessible but many degraded \\
\hline
\end{tabular}

The Millennium Assessment found that ecosystems have experienced greater change over just the past fifty years than at any other time in human history. Over $60 \%$ of the services (15 out of 24) were in decline while only four were improving. Three of these four improving services were related to food production, and all of these are involved in the production of commercial goods for which there are ready markets.

There are many causes for the declines, depending on the particular ecosystem service. Habitat development, for example, is a key driver behind the loss of wetlands in many parts of the world and, with them, the services they provide. Indeed, many commentators have argued that the devastation of the tsunami in southeast Asia was worsened by the destruction of mangroves for coastal development and the weakened of the services of flood and storm buffers. Pollution and overfishing are key causes of fishery collapse, and these, in turn, are driven by more fundamental drivers - the patterns and levels of consumption of the earth's growing population (MEA 2005).

\section{B. How Valuable are Ecosystem Services?}

The awareness of ecosystem services' importance is certainly not new. Plato wrote about the service of soil retention over 2,500 years ago (Daily 1997). But efforts to identify and calculate these services' valuable contributions to social welfare by ecologists and economists are surprisingly recent. Their research has demonstrated the extremely high costs of replacing many of these services if they were to fail. In a highlypublicized 1997 article in Nature, for example, a group of economists and ecologists estimated the value of nature's services at approximately $\$ 16$ to $\$ 54$ trillion per year; the globes gross product was estimated at $\$ 18$ trillion (Costanza et al. 1997).

One can equally consider a specific service, such as the soil's ecosystem service of providing nitrogen to plants. Nitrogen is supplied to plants through both nitrogen-fixing organisms and recycling of nutrients in the soil. If nitrogen were provided by commercial fertilizer rather than natural processes, the lowest cost estimate for crops in the U.S. would be $\$ 45$ billion, the figure for all land plants $\$ 320$ billion (Daily 1997). Such estimates are inherently uncertain, of course, but the extraordinary 
costs required to substitute for many important services by artificial means are beyond dispute.

While the estimated dollar value of these services is impressive, it is important to recognize that these are estimates with significant limitations. First, because most ecosystem services are not exchanged in robust markets (such as buying apples), there are no obvious prices to calculate their value. These economists have developed different ways to measure their economic value, all of which require extrapolation or assumptions. Consider a wetland, for example. An wetland ecosystem may be characterized either through its features (site-specific characteristics such as landscape context, vegetation type, salinity), goods (vegetation, mulluscs, fish), services (nutrient cycling, water retention) or amenities (recreation, bird-watching).

Economists divide these goods, services and amenities into separate categories. The most obvious category includes consumable ecosystem goods such as cranberries and crabs that are exchanged in markets and easily priced (direct market uses). Activities such as hiking and fishing (direct non-market uses) as well as more intangible existence and option values (non-market, non-use) are not exchanged in markets. As a result, their values must be determined indirectly by shadow pricing techniques such as hedonic pricing, travel-cost methodologies, or contingent valuation. Many ecosystem services are categorized as indirect non-market uses, for while they provide clear benefits to humans they are neither directly 'consumed' nor exchanged in markets. These are also classic public goods because their use cannot be exclusively controlled (Barbier et al. 1997).

The second challenge is that an ecosystem service's value is landscape-specific. The benefit to humans of an ecosystem is not a straightforward biophysical measure, for identical ecosystems in different locations will have very different values. The value of a wetland's nutrient trapping service, for instance, depends on the location of its out-flow. Does it flow to shellfish beds (high value) or a fast-flowing ocean current (low value)?

Third, policy makers must concern themselves with two different types of valuation. The first is the absolute value of the ecosystem service. Methods to determine this have been described above. These values may prove important for political or advocacy purposes. Knowing that wetlands provide billions of dollars of services to local communities may make it easier to adopt regulations restricting development of wetlands or other protective measures. The second type of measure is marginal value. The fact that pollinators annually provide Americans up to $\$ 1.6$ billion of service or that soil fertility is worth $\$ 45$ billion is important to know for general policy direction, but that fact does not help to inform specific land use or pollution permitting decisions. One clearly cannot divide the $\$ 45$ billion value of soil fertility by the nation's total agricultural acreage to determine the value of the services of five acres of land threatened by a specific development. Land use decisions are made on the margins, such as whether to allow development of ten hectares in a seventy hectare wetland. Absolute service values cannot inform this decision. Thus, the greatest need for ecosystem service valuation may be at the margins, determining how much is service provision worth in this particular location? 
Fourth, and related to the previous point, often times policy makers do not need to know the absolute value of a service at all, so long as it is obviously important. In deciding whether or not to invest in an ecosystem service or a technological service provider, the key question is relative cost. Which approach provides the needed level of service at lowest cost? If it costs $\$ 10$ million to build a treatment plant and $\$ 5$ million to institute land changes with the same resulting improvement in water quality, then investing in an ecosystem service makes financial sense irrespective of the absolute value of the water purification service. In this respect, valuing the costs of substitutes may be more important than valuing the absolute service.

In sum, ecosystem services make critically important contributions to human welfare and valuation can make this clear. Depending on the circumstances, policy makers may need to decide whether an absolute and marginal valuation is most useful.

\section{Why are Ecosystem Services Under-protected?}

Given the obvious importance of ecosystem services to our well being, one might assume that ecosystem services would be prized by markets and explicitly protected by the law. Despite their economic value and central role in provision of important public benefits, however, ecosystem services are only rarely considered or protected by the law (Salzman 1997). Nor, in the past, have significant markets arisen that capitalize on the commercial value of these services. The reason for this relative neglect is threefold: ignorance, institutions and market failure.

\section{i. $\quad$ Ignorance}

Perhaps the most basic reason we do not pay more attention to the provision of ecosystem services is that we take them for granted. We are ignorant of the sources of goods and services we depend on. To design policy instruments that efficiently provide services, at a minimum policy analysts must be able to identify services on a local ecological scale-detailing how they are generated and how they are delivered. We can make empirically sound predictions that actions on a gross scale, such as clearcutting, for example, will affect nutrient flows and services, or that a significant loss of animal and plant populations will reduce ecosystem resiliency. In the aggregate, such knowledge can provide policy guidance in warning against extreme actions. But landscape context matters. In most cases, our scientific knowledge is inadequate to undertake meaningful marginal analysis - to predict with any certainty how specific local actions affecting these factors will impact the local ecosystem services themselves. For example, it is difficult to predict how developing thirty percent of this wetland will impact water quality, flooding events, or local bird populations.

Ironically, this focus has been reinforced and, at times, driven by legal requirements. With few exceptions, it is fair to say that environmental laws around the globe were not designed with ecosystem services in mind. Legal protection of ecosystems and the services they provide simply were not primary objectives when the 
relevant laws were drafted. Generally speaking, laws addressing air pollution and water pollution rely primarily on technological or human health-based standards. Conservation laws protecting endangered species are species-specific. And planning under resource management laws are written to accommodate multiple and conflicting uses. Because these laws were not primarily intended to provide legal standards for conservation of natural capital and the services that flow from it and, as many authors have pointed out, in practice they usually do not (Salzman 1997).

\section{ii. Institutions}

A second obstacle to the protection of services is institutional. Political jurisdictions are rarely aligned with ecologically significant areas such as watersheds; instead, they exercise authority over areas defined by state, provincial, or municipal borders. Not surprisingly, environmental problems do not track political boundaries and it is difficult for multiple political actors to agree on the same course of action. More challenging, the costs and benefits of conserving ecosystem services may be separated across jurisdictions. Thus, for example, upstream and downstream jurisdictions will have very different views about the value of upstream forest conservation when it comes to water quality. As a result, consistent efforts to manage landscapes that ensure service provision are easily confounded by collective action problems. Seeking to overcome this obstacle, New Zealand and a number of Australian states in the last decade have created catchment management bodies that exercise land use planning authority throughout an entire watershed, but these remain a rare exception (Salzman and Ruhl 2001).

\section{iii. $\quad$ Market Failure}

The last reason services are difficult to protect lies in market failures. While some services are clearly valuable to social welfare, they may have little or even no market value. We have no shortage of markets, for example, for many ecosystem goods (such as apples or fish). People pay money for apples every day at the grocery store without a second's thought. But the ecosystem services underpinning these goods (such as renewal of soil fertility and pollination) are free. This does not mean that they have no value. Rather, the services have no market value for the simple reason that no markets exist in which they can be bought or sold. As a result, there are no direct price mechanisms to signal the scarcity or degradation until they fail (at which point their nonmarket value becomes obvious because of the costs to restore or replace them) (Heal et al. 2001).

Indeed, many ecosystem services may be described as "public goods." This is a term economists use to describe a good that is non-rival (consumption of the good by one does not reduce the amount left for others) and non-excludable (individuals cannot be excluded from consuming the good). Unlike an apple that can be bought and consumed by one person, all those who live in a country with secure borders and low crime rates benefit from these public goods, whether they pay taxes or not. Similarly, those who live downstream from wetlands benefit from the role wetlands play in slowing floodwaters, whether they paid to conserve the wetlands or not. 
In fact, many ecosystem services, ranging from flood control to climate stability, provide non-rival and non-excludable benefits. Because these services have no market price, they appear to be free and, as a result, are taken for granted (until their importance is recognized, too late, after their loss). Take the example of wetlands and their role as a nursery for young fish. The wetlands owner surely provides a benefit to fishermen and those who like to eat fish by providing the habitat for the minnows to grow and reach maturity. But these benefits are uncompensated. They are, in economists' terms, "positive externalities" provided by the landowner. The market value of the wetlands depends on its location, the pressure for coastal development, and the scarcity of alternative development sites. The positive externalities it provides simply are not part of the calculation. If the wetland is developed, the nursery benefits will be lost and overall social welfare may well decline, but this should be expected. There were no market signals to suggest they should have been considered in the transaction. Because we can easily value ecosystem goods such as timber or fish, we tend to invest in extracting these goods even if it means degrading the services that underpin their production.

Nor are these isolated examples. Because landowners generally are not paid for the services their land provides others, it should come as no surprise that they see few incentives to conserve or enhance the services they provide, nor are there obvious reasons they should take service provision into account when making land use decisions. This might not be critically important if most lands providing services were public property that could be set aside for conservation, but they are not. Private lands, including many lands used for agricultural production, are vital not only for biodiversity conservation but also for provision of many other services (Farrier 1995).

As a final point, it is worth noting that ignorance and public goods - the barriers to market creation - are related. Markets create knowledge. We have a very advanced understanding of how to manage farmland to maximize production of cash crops for the simple reason that they are cash crops. It pays to manage land efficiently for crop production. We have a much poorer understanding of how to manage land for ecosystem service provision, not because services have no value but because land owners cannot capture the value of the services their landscape provides. Agricultural markets provide very clear signals to farmers of the value of clearing wetlands to grow more crops; but there are no markets for biodiversity, water quality, or flood control to reflect the loss in benefits once the land is cleared.

\section{Why choose payments over other policy instruments?}

\section{i. $\quad$ Traditional environmental policy tools}

The preceding analysis demonstrated that ignorance, institutions, and market failure combine to make ecosystem services easy for the public to take for granted and difficult for private markets to provide. Thus the government has an important role to play in ecosystem service provision. Because a stable supply of public goods can provide great public benefit yet little private gain, one would expect that private markets will systematically lead to the under-provision of ecosystem services. To correct this problem 
of market failure, government can step in and act on behalf of the public. It is not obvious, however, that payments are the most appropriate form of government action to ensure service provision. In fact, governments traditionally have not relied strongly on payments to ensure environmental protection. When choosing which instrument to use in changing the behavior of landholders, the government can choose from a toolkit of five basic strategies. For convenience, one might call these the "Environmental Policy Toolkit" - prescription, penalty, persuasion, property rights, and, finally, payments (Salzman and Thompson 2007).

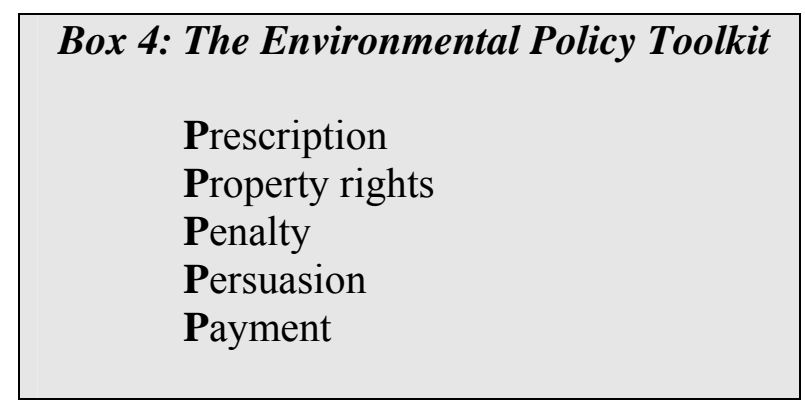

Through prescription, the government relies on command-and-control regulation, mandating certain behaviors, proscribing others, and imposing penalties for noncompliance. "You shall do this; you shall not do that." This is the classic approach for pollution control in industrial settings. Prescription has been used indirectly to ensure service provision from wetlands by prohibiting their development and to protect the service of biodiversity.

A related approach is one of property rights. This instrument relies on privatization and allocation of access to a resource, whether a right to a particular catch in a fishery or the ability to emit a quantity of air pollution. In many programs, such as the acid rain trading program in the United States or the European Union's Emissions Trading Scheme, these entitlements may be traded. In practice, property rights instruments often work in combination with prescription. Trading programs, for example, rely on regulations that ban certain activities, then create tradable property rights that permit the activity.

Financial penalties and charges modify behavior through the financial signals of taxes and fees. Such an approach does not ban certain activities outright but, rather, makes them more expensive (such as charging per head of cattle to graze on public lands or per kilogram of purchased CFCs).

Persuasion relies on an information approach, educating landholders of the consequences of their management practices on the landscape and informing them of alternate approaches. This is a common approach in many countries in the agricultural sector, where extension services provide counseling and technical support to farmers. The goal of this approach is self-regulation. 
The final approach is payment. This usually takes the form of a subsidy, either as a direct payment or tax break, justified by a public goods argument - society at large benefits from these activities but because of market failures does not pay for them.

To put these different instruments in the context of ecosystem services, take the example of water quality in Figure 1 below (Heal et al. 2001). Imagine that the municipal water supplier owns the upland forest, which naturally filters and cleans water as it flows through the upper watershed. Property owners in the farmlands are dairy farmers, grazing cows on their fields beside the stream that flows into the reservoir. The farmers could manage their land to provide an improved service of water purification by planting riparian vegetation buffers (i.e., erecting fences to protect strips of plants alongside the stream from grazing). Such vegetative buffers capture nutrients and provide the ecosystem service of reducing silt before it reaches the watercourse. Downstream water consumers benefit from these actions, which provide them with clean drinking water that does not require extensive pre-treatment. Farmers might benefit from reduced streambank erosion.

\section{Figure 1: A model watershed}

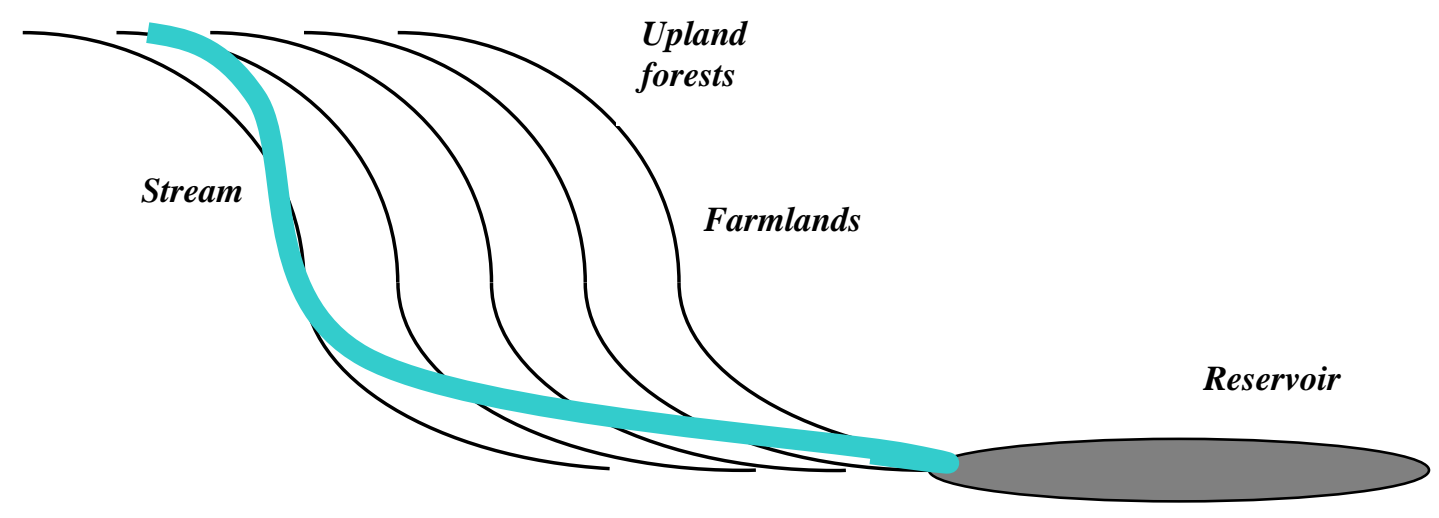

Traditionally, few land owners actually would plant riparian buffers. Farmers may well have been informed of the benefits of this practice for themselves and for downstream users, but it is unlikely that they would change their behavior because of the time and cost of fencing and the concerns over the loss of productivity from setting aside pasture. And those who did fence off their streams would bear all the costs, with no contributions from those downstream who benefit from the positive externalities of cleaner water.

So how could the government ensure clean drinking water? One might rely on engineering and build a pre-treatment plant. An ecosystem service approach of riparian buffers, however, would likely be less expensive. But which policy instruments would best ensure provision of services?

The traditional approach would likely impose prescriptive regulations to require farmers to plant riparian buffers. One could equally rely on financial penalties, levying a 
tax on farmers who do not have buffers, or trying to persuade farmers to put in buffers. These are set out in Box 5 below.

\begin{tabular}{|l|}
\hline Box 5: The Environmental Policy Toolkit in a watershed \\
$\begin{array}{ll}\text { Prescription } & \text { Regulations requiring riparian buffers } \\
\text { Property rights } & \text { Combine regulations with tradable right of buffers } \\
\text { Penalty } & \text { Tax farmers who do not have buffers } \\
\text { Persuasion } & \text { Pilot projects demonstrating benefits of buffers } \\
\text { Payment } & \text { Pay for planting of buffers }\end{array}$ \\
\end{tabular}

\section{ii. $\quad$ Payments for Ecosystem Services (PES)}

One could, however, view the issue from a totally different perspective. Why not, one might argue, simply recognize this situation for what it is - the provision of valuable services to consumers - and realize this through an explicit arrangement of payments for services rendered? Put another way, why not treat farmers' provision of ecosystem services as no different from their provision of other marketable goods? Farmers are certainly well accustomed to contractual arrangements for their agricultural products. Dairy farmers sign contracts to sell their milk; potato farmers do the same. Why not treat the provision of water filtration services as a similar business transaction, where farmers manage their land through riparian buffers and grass swales to "grow the crop of water quality" much the same as dairy and potato farmers do for their cash crops?

In many respects, provision of ecosystem services would be no different than supplying traditional farm produce, with the level of compensation dependent on the quality and level of services provided. Such exchanges would be arm's-length payments for services rendered, creating an ongoing incentive for the landholder to manage the property so that service provision is ensured. The concept behind payments for ecosystem services (PES) is very simple and set out in Box 6 below. Through this perspective, environmental protection can more closely resemble contracts between service providers and service beneficiaries than the object of governmental regulations.

\section{Box 6: The PES Concept}

The environment provides critically important services. Some of these are captured by markets, but many are not. They are positive externalities that are therefore regarded by the beneficiaries as free. As a result, many ecosystem services tend to be both under-conserved and undervalued. If beneficiaries had to pay for explicit service provision, however, governments would think differently about their policies and property owners would think very differently about sustainable land management practices. In basic economic terms, payments for ecosystem services (PES) 
seek to "get the incentives right" by capturing the positive externalities, by providing accurate signals to both service providers and users that reflect the real social benefits that ecosystem services deliver.

Government policies that recognize this basic fact, and that focus on landscape management to ensure and provide services, could result in increased social welfare but would represent a departure from traditional approaches to environmental protection, land use controls and service provision strategies.

The first insight of an ecosystem services perspective is that investing in natural capital can prove more efficient than using built capital to deliver key services. As an example, consider the case of flood control. One can address floodwaters through built capital, such as engineered works (e.g., construction and maintenance of dikes and levees) or through natural capital, such as landscape management (e.g., restoration of wetlands in flood plains). In some instances, perhaps many, landscape management may prove a better public and private investment strategy for providing flood control once one accounts for the positive externalities of improved water quality, wildlife habitat, and recreational amenities. As described in Box 7 below, the Catskills watershed's role in supplying water for New York City makes the point in a concrete setting.

\section{Box 7: New York City and the Catskills Watershed - Investing in Natural Capital Instead of Built Capital}

In the early 1990s, a combination of federal regulation and cost realities drove New York City to reconsider its water supply strategy. New York City's water system provides about 1.5 billion tons of drinking water to almost nine million New Yorkers every day. Ninety percent of the water is drawn from the Catskill/Delaware watershed, which extends 125 miles north and west of the city. Under amendments to the federal Safe Drinking Water Act, municipal and other water suppliers were required to filter their surface water supplies unless they could demonstrate that they had taken other steps, including watershed protection measures, to protect their customers from harmful water contamination.

Presented with a choice between provision of clean water through building a filtration plant or managing the watershed, New York City easily concluded that an ecosystem services approach was more cost effective. It was estimated that a filtration plant would cost between $\$ 6$ billion and $\$ 8$ billion to build. By contrast, watershed protection efforts, which would include not only the acquisition of critical watershed lands but also a variety of other programs designed to reduce contamination sources in the watershed, would cost only about $\$ 1.5$ billion. Through a stakeholder consultation process, after two years and more than 150 meetings, a 
Memorandum of Agreement was signed by sixty towns, ten villages, seven counties, and various environmental groups. Acting on behalf of the beneficiaries of the Catskills' water purification services, New York City chose to invest in natural rather than built capital. Nor is New York City alone. Many municipalities around the world use watershed conservation as a means of ensuring high drinking water quality.

Source: Daily and Ellison 2003

For the purposes of this report, PES refers to voluntary transactions where a service provider is paid by or on behalf of service beneficiaries for land, coastal, or marine management practices that are expected to result in continued or improved service provision. $^{2}$ The payment may be monetary or barter, and is intended to defray or compensate the costs of service provision. As we shall see, the term, "PES schemes," covers a very broad landscape. PES schemes can include many different types of parties - from farmers, communities and taxpayers to consumers and corporations. PES schemes can occur over very different scales-from pollination of local farms and erosion control in a watershed to regional protection against flooding and consumers paying for a cup of "shade grown" coffee beans half a world from where they were grown.. And PES schemes can span a wide range of transaction types-from one-off payments for a biodiversity offset to arms-length market transactions for carbon credits.

\section{Box 8: PES Definition}

PES refers to voluntary transactions where a service provider is paid by or on behalf of service beneficiaries for land, coastal, or marine management practices that are expected to result in continued or improved service provision. ${ }^{3}$

\footnotetext{
2 There exists a wide range of PES approaches and, not surprisingly, a variety of terms have been used to describe PES, including "Market mechanisms for environmental services" (Landell-Mills and Porras 2002; Pagiola, Bishop and Landell-Mills 2002, and Wunder 2005), "Compensations for environmental services (Rosa, Kandel and Dimas 2003), Rewards for environmental services (PRESA 2009), and Agrienvironmental payments (OECD 2009).

3 The definition of PES by Sven Wunder et al. has also gained serious attention in the literature. They define PES as having five attributes (Wunder 2005):

1. a voluntary transaction where

2. a well-defined ES (or a land-use likely to secure that service)

3. is being 'bought' by a (minimum one) ES buyer

4. from a (minimum one) ES provider

5. if and only if the ES provider secures ES provision (conditionality).
}

The shortcoming of this definition is that only a small percentage of PES schemes satisfy Condition 5. As Section II.G. explains, with the exception of carbon markets, most PES are based on inputs (i.e., land management practices) rather than outputs (i.e., a measurable change in service provision), whether this increases the service provision or not. Indeed the authors notes that "there are probably very few "true 
In choosing among policy instruments to increase service provision, it is helpful to think of PES design as a problem of asymmetric information. There is no doubt that landowners know their property better than the government. Landholders know both the opportunity cost of a specific land use change and the price they are willing to accept to implement this change. For its part, the government agency or water supplier knows how much it is willing to pay and which types of land use changes would be most valuable for service provision. The design challenge is how most efficiently to transfer both types of information-(1) willingness to pay/accept, and (2) service provision resulting from a land use change - from one party to another in a mutually reinforcing fashion.

Prescriptive measures are inefficient at information exchange for the simple reason that they are primarily a one-way discussion- the government telling regulated parties what they can or cannot do. The farmer's knowledge of which land use changes are least costly is ignored. Financial penalties suffer the same shortcoming. It falls entirely on the government to determine not only which actions to encourage or discourage, but also how much financial penalty is needed to induce the appropriate behavior.

And what about payment schemes? At their core, markets are simply an exchange of information about willingness to pay and willingness to accept. The market mechanism necessitates that each side reveal information to the other. Indeed, if set up carefully, payment schemes can shift the information burden to the landowners.

In defining what we mean by PES, it is equally important to be clear what the term does not include. In particular, PES schemes are a subset of market-based instrument, but the term does not include all market-based instruments that promote environmental protection. The well-known acid-rain trading program in the United States, for example, provide a very important model for designing cap-and-trade programs, but it is not a PES. The environmental protection results from reduced emissions from coal-fired power plants. There are no land, coastal or marine management practices involved. Similarly, taxes on leaded gasoline are an effective means to promote air quality, but they are not a PES. Thus, PES is not a general abbreviation for market-based instruments.

While the principle of PES is simply stated - those who benefit from service provision should pay the providers - this is far easier said than done, for the equally simple reason that ecosystem services are take for granted. Because it is difficult to prevent someone who did not pay for an ecosystem service from benefiting from it, it is equally difficult to get such people to pay for provision of these services. Why pay for something when you have always gotten it for free? As a result, a key challenge in implementing a PES approach lies in creating a market where none exists - in capturing the value of the service by compensating the providers for the positive externalities they

PES' conforming to the theoretical concept developed in the literature and described in the simple definition." 
provide. This approach, notably unlike that of traditional regulatory or tax instruments, views environmental protection much as a business transaction between willing parties.

When successful, PES create positive economic incentives for land owners to conserve or even improve the function of their lands for services as varied as watershed protection, carbon sequestration, or biodiversity conservation. This can increase land owners' awareness of the true value of their properties. In the process, PES schemes may bring new resources and new incentives to conservation, a particularly important development when funding for conservation is scarce.

\section{iii. $\quad$ Types of Services Receiving Payments}

As Section A.I. described, there is a broad range of ecosystem services. Not all of these, however, are amenable to PES. Indeed, if one looks at the PES schemes operating or in pilot phases around the globe, payments cluster around four broad types of services.

The first is watershed protection. This includes the ecosystem services of water purification, enhancing/ensuring water quantity, flood control, erosion control, and others. In general, downstream beneficiaries pay upstream land owners either for adopting particular land uses or maintaining current land uses. Payments for water services benefit from the advantages that it is relatively easy to identify both the providers and the users of these services and, equally important, the users are generally discrete-private operations such as hydroelectric facilities and industrial users-or institutions that represent groups of users such as municipal water authorities (who act on behalf of the public) or irrigation districts (who act on behalf of the irrigation farmers). All of these parties have an obvious and direct interest in service provision. Moreover, the beneficiaries, particularly water users, are used to paying for water, already. Indeed, water services are the most common PES scheme around the globe (Landell-Mills and Porras 2002).

The second type of service found in PES schemes is carbon sequestration. Depending on how the climate negotiations conclude, the sequestration of carbon by reforestation, afforestation, and land use may end up dominating all the other PES schemes combined in terms of total value. The classic example of such a PES scheme is a large emitter of carbon dioxide in a country that regulates greenhouse gas emissions paying a land owner to plant additional trees. In exchange for the additional carbon now sequestered, the company obtains credits it can use to offset its greenhouse gas emissions. In contrast to watershed services can operate at the regional, national or global scale, though the trend seems to be increasingly toward national and global markets.

The third service receiving payments is biodiversity conservation. Because biodiversity is such a classic public good, the PES here are smaller and more discrete. While there are isolated examples of species habitat banks, biodiversity payments can take a wide range of forms, including purchase of conservation easements, payment for bioprospecting rights or research permits, hunting and fishing licenses, and management contracts to 
conserve and restore habitat. Not surprisingly, most of these payments operate at the local or perhaps regional level.

The last service category where one finds PES schemes is landscape beauty. The most obvious example of this is eco-tourism, where tourism operators pay a local land owner or community not to hunt in certain areas or to engage in particular land management activities. This approach has run into criticism that few meaningful payments from eco-tourism actually end up in the hands of locals. Nonetheless, as development pressures increase, the value of natural and beautiful places will increase, as well, raising at least the potential for greater revenue flows toward eco-toursim.

In reviewing these four categories, an obvious question arises. Why has it been easier to create PES schemes for these types of services than for others? What is it about watersheds and carbon sequestration that make payments schemes easier to design and implement? Section II, that now follows, explains the critical design elements underpinning a successful PES scheme.

\section{Designing PAYMents for Ecosystem SeRVices}

In designing a PES transaction, five basic questions must be considered. The first concerns what specific service needs to be provided and, as a corollary, whether landscape management can provide this service. The second question focuses on the providers and beneficiaries. Unless these two groups, sellers and buyers of these services, are discrete then PES will be very difficult. The third question addresses the level of service that needs to be provided and whether this can be adequately monitored. If the linkage between landscape management and service provision is poorly understood, then the buyer will have little confidence it is receiving value for its payments. The fourth question asks which type of payment mechanism is most appropriate. This will depend on a range of factors, starting with the nature of the service, the scale of service provision, the buyers and the sellers. These questions are the subject of Part II of this report. Part IV turns to challenges in designing PES schemes and, in particular, whether the supporting mechanisms are adequate. These can range from the rule of law (i.e., assurance that agreements will be honored and enforced) to intermediary brokers that bring buyers and sellers together.

\section{Box 9: Key PES Design Questions}

- What is the service being provided?

- Can landscape management efficiently provide the service?

- Who provides the service and who benefits?

- Are there discrete groups of providers and beneficiaries?

- What level of service is needed?

- Can this be adequately monitored?

- What is the most effective payment mechanism?

- Direct payment, mitigation and offsets, or certification?

- Are the supporting institutions adequate? 


\section{A. What is the service being provided?}

In crafting payments to ensure ecosystem service provision, the very first question one must consider is which service matters or, more to the point, whether the problem one seeks to address can effectively be addressed by land management - can ecosystem service provision through land management address the problem? If landscape management either cannot provide adequate service provision or cannot do so costeffectively, then a PES scheme may prove ineffective.

This seems easy to determine in the case of local biodiversity. Biodiversity is best provided through conservation of remnant native habitat. If the problem is erosion, the ecosystem service of soil retention can be provided through plants' root systems. If the problem is water quality, ecosystem services may provide a cost-effective source of provision, as well. Looking to the Catskills example, the New York City water authorities determined that water quality could be achieved more cheaply through landscape management than through construction of a water new treatment facility.

Policy makers must take care to be specific, however, about the nature of the desired service. Within the suite of watershed services, for example, there are important differences. As Sven Wunder has noted (Wunder 2005),

Even within specific service categories, there are differences. Domestic water supply systems require a constant flow and high quality, but hydroelectric power producers with reservoirs usually prize total volume and care little about water quality except for the absence of sedimentation. The willingness to pay of a given group of beneficiaries will depend on the specific service they receive, on the value of that service to them (compared with the cost of alternatives), and on the size of the group.

It is important to recognize, as well, that ecosystem services may not always be the best option for service provision. In a densely-populated, urban area, for example, one can easily imagine that landscape management might prove to be more expensive than a water treatment plant, either because of high land costs or because the natural services would prove inadequate to filter the water. If New York City's source of drinking water had been a local watershed rather than one located over 100 miles away, local land management may not have been sufficient to protect water quality.

PES designers must also pay careful attention to modeling and assumptions about causation. The relationship between land management and service provision is not always obvious. It has long been assumed, for example, that forests act as sponges, regulating water flow over time and ensuring higher levels of water quantity. This is often the case, but there has been an increasingly heated debate over whether it is always true (cite). Local land patterns need to be considered. As one report noted (IUCN 2006), 
Montane cloud forests are known for their very high water production capacity, which has been traditionally ascribed to stripping of water by the forest canopy from frequent fog. It was feared therefore that clearing of cloud forest would cause streamflows to diminish. Recent evidence from Costa Rica has shown, however, that the overall hydrological impact of cloud forest conversion was close to neutral, because reduced cloud stripping was more or less balanced by the lower water use of grassland.

Some services are easier to model than others. The relation between deforestation and erosion or biodiversity conservation, for example, is better understood than its effect on hydrology. At the outset, therefore, PES designers need to explicitly challenge their assumptions about service provision. It is hard to think of a worse outcome for a PES scheme than supporters making unfounded claims that payments for land management will result in particular levels of service provision.

Similarly, PES designers need to be clear at the outset about trade-offs. Land management practices to maximize one type of service may result in reduction of another service. A classic example in this regard is the relationship between afforestation and water levels. Plantations of fast-growing trees such as eucalyptus may increase carbon sequestration, for example, but they can equally harm biodiversity, lower water availability, and reduce streamflows because of evapotranspiration and a lower water table (Jackson 2006). Equally, though, provision of some services some can also increase others. Maintenance of natural areas can both enhance biodiversity and pollination services. The report addresses bundling of services below in Section C.i. below.

\section{B. Who provides the service and who benefits?}

A precondition for any market exchange must be willing buyers and sellers. Not surprisingly, buyers and sellers are motivated by different concerns. The primary concern of service buyers is a perceived current or future threat to their service provision. This may seem obvious, but it is an important point. For example, unless water consumers recognize a real and impending threat to their supply of clean water (e.g., through increased development of the forested upper watershed), there is no reason to pay the upper watershed landowners to keep the forest intact. If the forest were not threatened by development, PES would seem nonsensical since the consumers would continue to receive the service of water provision with our without payments. They can continue to act as free riders, enjoying the positive externalities provided by the upper watershed owners. Similarly, absent the threat of damage from storm surges, there is little reason for the beneficiaries of the service of storm protection to pay for conservation of wetlands and mangrove stands. In a clear example of this, following the destructive impacts of the hurricane Katrina on New Orleans, the state of Louisiana has started directing funds directly toward coastal wetlands restoration. Prior to the storm, by contrast, the state supported policies that degraded wetlands (Flournoy and Verchick 2005).

Put simply, if a land use provides valuable ecosystem services but they are neither widely recognized nor appreciated by beneficiaries, it is unlikely that a market for 
services will arise in the absence of government intervention. Thus, education and outreach may prove an important part of designing a PES program. It is critically important that beneficiaries understand why they should pay for service provision (either directly or indirectly through government payments).

Another precondition for functioning markets is the presence of discrete providers and beneficiaries. Economists describe this as a problem of collective action. Unless a relatively small number of providers and beneficiaries can get together, transaction costs become too high for contract formation. The public goods nature of many services makes this a real concern. Biodiversity, for example, benefits agriculture through the insurance service of genetic diversity and benefits pharmacology through provision of antibiotics and other medicinal compounds. The problem is that we all gain from these benefits, yet there is no sufficiently discrete class of beneficiaries with whom landholders can negotiate, and the transaction costs of gathering enough beneficiaries together to negotiate for the service are too high.

Thus it is no surprise that private purchasers of biodiversity's benefits are hard to find, which explains why there are so few true markets for biodiversity. For the same reason, one can also understand why so many examples of PES are found in the area of water quality. Most water consumers are not only used to paying for potable water, but can be collectively represented in a transaction by a single public body such as a water utility or local government.

Put simply, if a land use provides valuable ecosystem services but they are widely enjoyed by diffuse beneficiaries, it is unlikely that a market for services will arise in the absence of government intervention. This point has critical implications for the design of PES mechanisms.

In order to overcome collective action problems, most successful service markets to date operate as monopsonies, with only one buyer paying multiple service providers. It is inconceivable that the water users in New York City could have negotiated with the communities and land owners in the Catskills watershed. Only because a single purchaser, namely New York City's water authority, could act on their behalf was the PES scheme possible. Nor is this solely the case for watershed services. In the case of biodiversity, as well, the government pays for services on behalf of the citizenry. Such actions are entirely appropriate, it should be noted, since they correct the market failure posed by public goods.

Nor are monopsony buyers limited to governments alone. One might argue that water utilities and energy companies operate in a quasi-governmental capacity, but purely private markets often act as monopsonies, as well, with single buyers and multiple sellers. Consider, in this regard, the case of Perrier Vittel, described below in Box 10.

Box 10: Perrier Vittel payments to farmers

Perrier Vittel is the largest bottler of mineral water in the world. In the 
early 1990s, seeking to reduce the nitrates and pesticides from farming operations entering the springs around its bottling operations in northeastern France, Perrier Vittel employed a range of payment mechanisms to change land uses in the catchment area. For an estimated $\$ 9$ million, Perrier Vittel paid above-market prices to purchase 1500 hectares around its water springs. In an innovative move, Perrier Vittel signed long-term (eighteen to thirty years) contracts with forty farmers, paying them $\$ 230$ per hectare to use more sustainable dairy farming techniques. The net result of these initiatives has been a reduction in non-point source pollution and significant changes in local dairy farming and animal waste management practices while eliminating corn cultivation and use of agricultural chemicals.

Source: IUCN 2006

\section{i. $\quad$ Potential buyers}

Depending on the ecosystem service, there is a wide range of potential buyers. These are briefly set out below.

\section{Government bodies}

As described above, when services are public goods or there are diffuse beneficiaries, it may be necessary for the government to step in and act on behalf of those benefiting from the services. The appropriate level of government depends on the scale of service provision. This might include government payments to landowners for the services of water quality (local government), flood control (regional government), or carbon sequestration and biodiversity conservation (national government).

\section{Corporations}

When services are provided to discrete beneficiaries, private PES buyers may be willing to pay providers to ensure continuous provision. Thus a hydroelectric company may be willing to pay upper watershed landowners to keep their forests intact in order to maintain the service of erosion control (so the lake behind the dam does not silt up). Similarly, ecotourism operators may pay a local community to ensure conservation of attractive biodiversity in the surrounding areas.

Corporations may be motivated by indirect market concerns. Pressure from environmentally-conscious consumers, for example, may cause a company to source its products or raw materials from supplies that have been certified as sustainably harvested, for example. They may pay for service provision because of pressure from shareholders or consumers demanding improved corporate social responsibility. In both cases, the company seeks to improve its image. Thus, for example, a company engaged in land development may voluntarily offset its harm 
to local biodiversity by voluntarily restoring and enhancing habitat elsewhere (BBOP cite).

Corporations may pay for services because of regulatory requirements for offsets. As described below, a company engaged in land development may be required to offset its harm to local biodiversity by voluntarily restoring and enhancing habitat elsewhere. The same offsite mitigation requirement may be true for a company that drains and fills a wetland. Done properly, these mitigation projects conserve the provision of ecosystem services.

\section{Consumers}

A category of consumers may wish to direct its purchases toward companies and products that act in what they view as an environmentally responsible manner. Eco-labels and certification programs can provide information to guide the purchasing behavior of these "green consumers." If enough consumers wish to buy certified products, then suppliers and retailers will respond to this market demand.

\section{Nonprofits (environmental groups, philanthropies)}

Not all buyers of services are motivated by profit. Conservation groups and land trusts may routinely pay land owners to conserve biodiversity as part of their groups' central mission. Similarly, philanthropies may fund service providers in order to ensure continued provision of an undervalued public good.

\section{a. Private versus Public Buyers}

As noted above, most PES schemes with public buyers operate as monopsonies. This can make sense because it overcomes both the challenge of collective action (the costs of organizing all the different beneficiaries) and the challenge of public goods (where there is no ready market for the service, despite its importance to social welfare). As a result, the public body acts on behalf of its citizens, ensuring provision of an important services. Public buyers offer other advantages, as well. With only one buyer, service purchases can be more comprehensive. It there is a regional plan to service provision, for example, having only one buyer ensures that the individual payments are strategic and part of a larger plan. Having only buyer may also lead to fewer transaction costs. In addition, the background threat of regulation in place of PES has more credibility.

Not surprisingly, reliance on public buyers offers potential disadvantages, as well. First, governments operate through bureaucracies and this may actually raise transaction costs depending on the layers of administration involved. Expenditure of public monies generally requires legislative authorization, rules over eligibility, terms of payment, monitoring protocols, opportunities to appeal adverse decisions, etc. Moreover, public bodies are vulnerable to political influence. It is easy to imagine PES schemes being 
created or converted over time to operate as generous subsidies to particularly influential interest groups (Echevarria 2005). Some have claimed, for example, that the CRP's survival and large funding is due more to its role as a subsidy for farmers than its role in service provision. Finally, public bodies are generally funded annually and, depending on politics and other pressing needs, may not receive the regular stream of funding necessary to maintain PES schemes in operation. Receiving money to pay PES providers one year is no guarantee that similar levels of funding will be available in future years.

Private purchasers, by contrast, may be able to ensure steady funding streams over longer periods of time. Competition among private buyers can drive the price of services up, creating greater incentives for service provision. Private purchasers are also less directly vulnerable to political influence. More purchasers, however, may also increase transaction costs.

In general, one sees private purchasers in cases of regulatory compliance. For example, a land developer is required by regulators to purchase credits in order to mitigate or offset the harm they have caused by their development activities. Wetlands mitigation banking is one example of this. Larger numbers of private buyers are likely when the PES scheme resembles a commodity and there is opportunity for brokerage and arbitrage. The increasing size of the carbon market, for example, and the fact that carbon credits are fungible (because one ton of sequestered carbon is much the same as another) creates the opportunity for market actors to profit by taking advantage of inefficiencies in pricing (e.g., buying the credits and selling them later, or betting that the credit value will go down). For biodiversity PES, by contrast, each species and habitat is different, making large-scale trading more difficult.

\section{ii. $\quad$ Potential sellers}

Just as the primary motivation for buyers is a perceived current or future threat to service provision, the primary motivation for sellers is marginal profit. As an example, consider the example described earlier, where water quality is threatened by runoff from farm fields. Currently, farmers' cows graze right up to the streambank and their manure affects harms drinking water sources downstream. Those who rely on water quality downstream are willing to pay the upstream farmers to plant a ten foot border of vegetation. This will reduce runoff by increasing the ecosystem service of nutrient uptake by the plants. If the farmer's primary motivation is maximizing profits, he will be interested in modifying his land use so long as the payments are the same or greater than what he would earn from current practices. When the current land use is more profitable than an alternative that provides greater services, a PES approach will often be ineffective unless it can make up for the lost profits. It is at the margins, comparing the marginal gain or loss from shifting land uses that PES operate. As Sven Wunder has observed (Wunder 2005),

PES is thus most useful in the intermediate range of positive but numerically small opportunity costs: degraded pastures, marginal croplands, forests in slowmoving agricultural frontiers, etc. Like other economic incentives, PES makes the 
most sense at the margin of profitability, when small payment to landowners can tip the balance in favor of a desired land use.

One can usefully divide service providers into two broad categories. The first is sellers who are paid for change. That is, payments are made to land owners willing to change their land use so that it provides greater services. For example, buyers interested in biodiversity conservation may pay land owners to removing invasive species from their property and put in fencing to keep out predators. Without these payments, the land use changes would not occur.

The second category of sellers is closer to insurance. It includes those who currently provide services. The goal here is to maintain the status quo. Thus, for example, in Costa Rica, a hydroelectric power company has been paying landowners in the upper watershed to keep their lands forested, described in Box 11, below.

\section{Box 11: Payments by Energía Global for service of erosion control}

Energía Global, a private hydropower company located in the Sarapiqui watershed, provides electricity for about 400,000 consumers. The company wanted to protect the watershed to increase the reliability of streamflow throughout the year and to reduce sedimentation. Through FONAFIFO [a government institution established to bring together ecosystem service buyers and sellers], Energía Global pay owners of upstream private land to reforest their land, engage in sustainable forestry or conserve forest cover. Landowners who have recently cleared their land or landowners planning to replace natural forest with plantations are not eligible for compensation. Energía Global pays US\$18 per hectare to FONAFIFO, which then adds an additional US\$30 per hectare. FONAFIFO makes cash payments to landowners who have signed contracts with Energía Global. Total payments of US\$48/hectare/year are related to the opportunity costs reforestation or forest conservation, such as potential revenues from cattle ranching. A local NGO, FUNDECOR (Fundación para el Desarrollo de la Cordillera Volcánica Central), oversees the implementation of the conservation activities, carries out technical studies and administers the scheme.

Source: IUCN 2006

In simple terms, Energía Global is concerned with sedimentation of the lake behind their hydroelectric dam. The service of sediment retention provided through forest conservation prevents the lake from filling up with runoff. Hence the goal of these payments is explicitly not to change the land use but, rather, to maintain current practices. The payments ensure the flow of services will continue into the future. 
The same marginal analysis occurs as described above, except in this case the comparison is between profitability from the current use versus profitability of future uses that would degrade service provision. Thus, for example, fishermen are beneficiaries of wetlands' role as a nursery for immature fish. If the wetlands owner were considering destroying the wetlands for a housing development, the fishermen might be willing to pay him to maintain the wetlands in their current state. Therefore the buyers must be willing to pay at least the marginal profit of what the land owner would have received by the development (i.e., the lost opportunity cost). In practice, such payments operate much as an insurance policy for continued service provision.

In either case, whether changing current land uses or maintaining them, the key point is that PES will be most effective when the payments make land uses marginally more profitable than alternative land use activities. At the same time, it is important not to focus exclusively on marginal profits. A number of PES schemes have found that land owners may be willing to bear some of the costs for service provision themselves because, for example, they take pride in their property's biodiversity (Stoneham 2002).

As with buyers, there is a range of sellers of ecosystem services, depending on the service.

\section{Private Landowners}

In many countries, most ecosystem services are provided by private lands. These are often agricultural lands, including crops, grazing and silviculture. While oneto-one exchanges between buyers and private landowners are possible, collective action problems are significant. There are high transaction costs to single negotiations and gathering together enough sellers to achieve a significant level of service provision may be difficult. This is particularly challenging for smallscale and low-income land owners in many rural areas (particularly in developing countries) who face an information constraint and may lack clear legal title to the land.

To overcome some of these problems, landowners may organize into a private association so they can negotiate with a single voice, better protect their interests, and increase the overall level of service provision for sale. Such collective organization also allows sellers to "bundle" different services together.

\section{Public Landowners}

Public bodies control large amounts of land in some countries, and may negotiate for service payments. Equally, a community group may sell services from communally held land or from land where community members have specific property rights (such as grazing or cropping). In some countries, the payment to public bodies for service provision has been controversial. Critics argue that these lands are public; therefore they already belong to the people. If so, then it is improper to charge the public for services provided by their own lands. 


\section{Mitigation Providers}

In countries with offset requirements for development, private parties may create mitigation banks and sell "credits." This happens in the United States with wetlands mitigation and in some states with endangered species habitat.

\section{Certification Organizations}

It is worth noting that those who are directly paid may not be the provider of services. In certification systems, for example, the certifying body is often paid a licensing fee by the supplier for use of its eco-label. The certification indicates that the seller is operating in a sustainable manner (e.g., shade-grown coffee) and this, in turn, signals consumers that they should buy this product rather than others that are not labeled.

\section{What Level of Service is Needed?}

So far we have identified the service to be provided, how it is provided, and who the providers and beneficiaries are, but we still lack one critical piece of information - the level of service provision. At the end of the day, the two most important aspects of any transaction are what you are paying for and how much you pay. In designing a PES program, we need more precision than simply identifying potential polluters and service providers. This is true for environmental protection more generally. If we choose to regulate, we need to know whom to regulate, which actions should be proscribed, and by how much. If we decide to tax, we need to know not only whom to tax, but also how much to charge. If we end up choosing a payment instrument, we need to know not only whom to pay, but also how much to pay them.

This is a critical point to understand. It is not enough to know that riparian fencing throughout a watershed is a good thing because it will improve water quality. Given the reality of limited budgets, the key question becomes which riparian stretches need to be fenced off to provide the greatest level of water purification. In other words, given the many potential service providers, PES programs need to determine whom to pay and, equally, whom not to pay. This is necessarily a landscape-dependent judgment and can raise a number of challenging issues.

Using the hypothetical watershed in Figure 1, for example, one might identify the service providers of water purification as all landholders whose properties border the catchment watercourses. After all, every landowner with vegetation bordering the river provides some water purification services. But PES programs do not have unlimited budgets. Buyers need more precision than simply identifying potential service providers. They need information on the specific categories of providers, where they are, and the particular impacts they cause on service provision.

To represent this graphically, Figure 2, below, shows a normal distribution of service provision from land care practices in the catchment. At one end of the bell curve 
will be those who currently provide low levels of water purification services. They are balanced at the other end by those whose land provides high levels of purification services (Salzman 2005).

\section{Figure 2: Distribution of service provision among farmers}

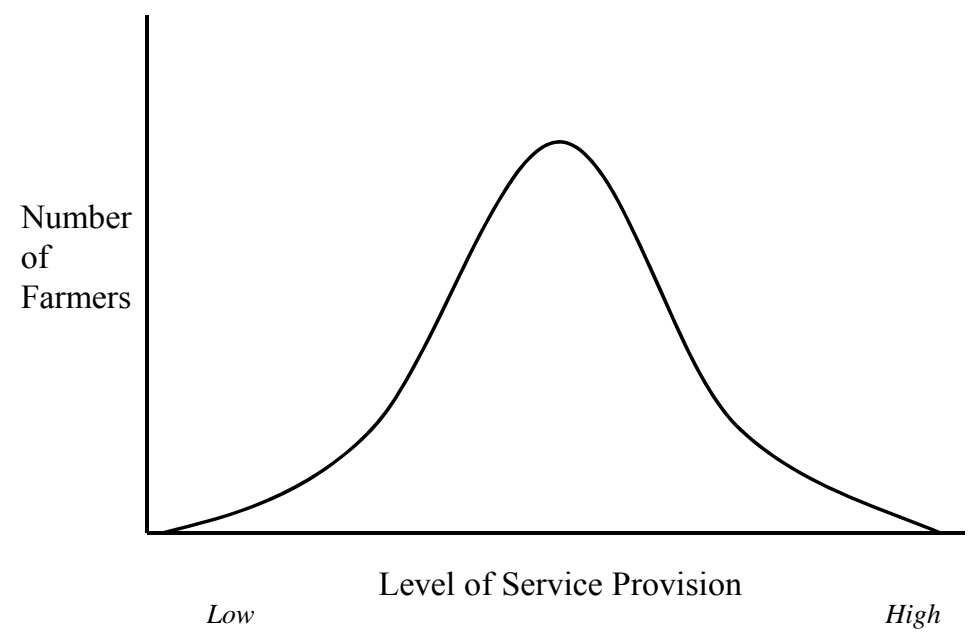

As should be clear from this figure, landscape context matters. For most services, provision is heterogeneous. Certain properties provide greater service levels than others because of where they are located. A farm bordering a river (represented on the right side of the curve) will be more important in providing water purification than a distant farm (represented on the left side of the curve).

Determining the level of service requires identifying the biophysical pathways of service provision. If the service in question is nutrient reduction, what are the landscape processes that keep the nitrates and phosphates from fertilizers and manure out of the watercourses? Such an analysis leads to a better understanding of which landscape management practices need to be encouraged by the policy instrument (such as riparian vegetation or swales) or, conversely, those that need to be discouraged (such as land clearing).

Consider, for example, the pilot program to combat salinity along the Macquarie River in Australia, described below.

\section{Box 12: Payments by Macquarie River Fruit and Fibre for Evapotranspiration}

Underneath much of Australia the groundwater is saline, a remnant of the vast salt sea that used to sit atop the continent. In the drive to settle and tame the country, settlers were often required to clear most of the native vegetation before they could claim title to the land. As a result, the ecosystem service of evapotranspiration that had long served as a water 
pump to keep rainwater from reaching the groundwater table well below the surface was seriously weakened. Large expanses of agricultural areas now face the serious threat of salinity - saline groundwater rising to the root zone of plants and stunting their growth. One area that is just starting to feel this effect is the verdant Macquarie River valley.

As a pilot program to combat salinity, in 1999 New South Wales State Forests signed a contract with Macquarie River Food and Fiber (MRFF, an organization that represents more than 600 Macquarie Valley irrigation farmers and their families) to purchase "salinity control credits." In simple terms, rather than mechanically pumping groundwater to keep the water table below the root zone of cash crops, MRFF purchased the ecosystem service of evapotranspiration by paying grazers to plant 100 hectares of native forest in the upper Macquarie River catchments (which, in theory, should lead to a reduction in groundwater levels in the lower catchments). The project provided valuable public relations benefits and improved relations between the irrigation farmers (who had been making money) with the sheep farmers (who had not). In theory, this scheme could provide the extra income that would make timber production a profitable undertaking in traditional grazing areas that have been considered marginal tree cropping country. It could also provide a steady income stream that can prove significant during lean crop years.

The key challenge in the project has been biophysical uncertainty over service provision - the link between upstream revegetation efforts and downstream salinity reduction. The trees were planted in "salinity hot spots" (i.e., known groundwater recharge zones) and estimated to transpire 53.5 megalitres per hectare over ten years. It was not known, however, whether this change in land use and resulting transpiration would lead to any measurable reduction in salinity downstream. Because of the complex hydrology, it was not even known how much land use change is needed for significant salinity changes. Given the poor understanding of how the service is provided and the time lags involved, MRFF chose not to expand the pilot project until it had more confidence in the investment needed (i.e., the amount of upper catchments revegetation) to cause a significant reduction in lower catchments salinity levels.

Source: Salzman 2005

Put simply, for a PES program to succeed over the longer term, the buyers must be confident that the landscape management they pay for will, in fact, lead to either improved or continued service provision. This is fundamentally a scientific question, and requires a clear understanding of the biophysical pathway between landscape activity, service provision, and service delivery. As a result, some services will be easier to develop markets for than others, for the simple reason that those buying services will be 
more confident in exactly what they are paying for-in ensuring they receive value for money.

PES designers must therefore consider, for example, whether they can confidently estimate the contributions of individual land management decisions in the upper watershed to water quality in a the lower watershed? Is this determination more similar to assessments of local biodiversity or to salinity control? The success of a PES scheme depends critically on the accuracy and cost of such assessments and, by extension, the creation of assessment methodologies for use in the field. We discuss the issues surrounding monitoring in more detail in Section III.A., below.

\section{i. $\quad$ Bundling}

Some ecosystem services are known as "umbrella services," because land management activities necessary to provide these services often results in provision of other services, as well. Protecting a forested upper watershed for the service of erosion control, for example, may also conserve biodiversity, reduce flooding, and improve water quality, as well. "Bundling" or "stacking" services refers to the practice of selling revenue streams from multiple services provided by the same plot of land. There is significant debate over this practice at the moment, with some carbon certification schemes maintaining that land credited for carbon sequestration cannot also receive payments for services such as biodiversity conservation. Others contend that the more service payments available, the better, since this increases the incentives to manage lands in a sustainable fashion. As a Forest Trends report has observed (Forest Trends 2006),

The level of payments in most PES are not, under current market conditions, generally high enough to fully offset opportunity costs or cover necessary investments for the change in land use. It is thus essential to have complementary income flows, either from commercial and subsistence products from the resource, or from payments for other ecosystem services...

Indeed, it is feasible to manage for multiple services. For example, carbon sequestration or storage services can be bundled with most other ecosystem services that involve re-forestation or vegetation, adding soil organic matter, etc. In these cases, the most common limitation to bundling is the requirement that payments be for "additional" ecosystem services provided and buyers refuse to pay for services already flowing. The rules established for CDM and other carbon trades are hampering bundling in this way.

\section{Service Payment Mechanisms}

While it has become commonplace to speak of "PES markets," in fact, few true markets for PES exist. With the exception of carbon credits, it is rarely the case that multiple buyers and sellers are exchanging the same good on an open market. Rather, as described above, most PES schemes a single buyer purchasing service provision from one or multiple sellers. 
While one can divide the types of PES mechanisms into many different types of categories, at a broad level there are three basic types-direct payment, mitigation and offset payments, and certification. Within these classes, there are many different mechanisms a PES designer should consider. These are set out in Box 12 below. Which mechanism is most appropriate will depend on a number of factors, including the type of service, the legal setting, whether the parties are public or pri vate, the difficulty and cost of obtaining information, the availability of funds, the supporting institutions, etc. Each mechanism is described below, with examples and analysis of the relative advantages and disadvantages.

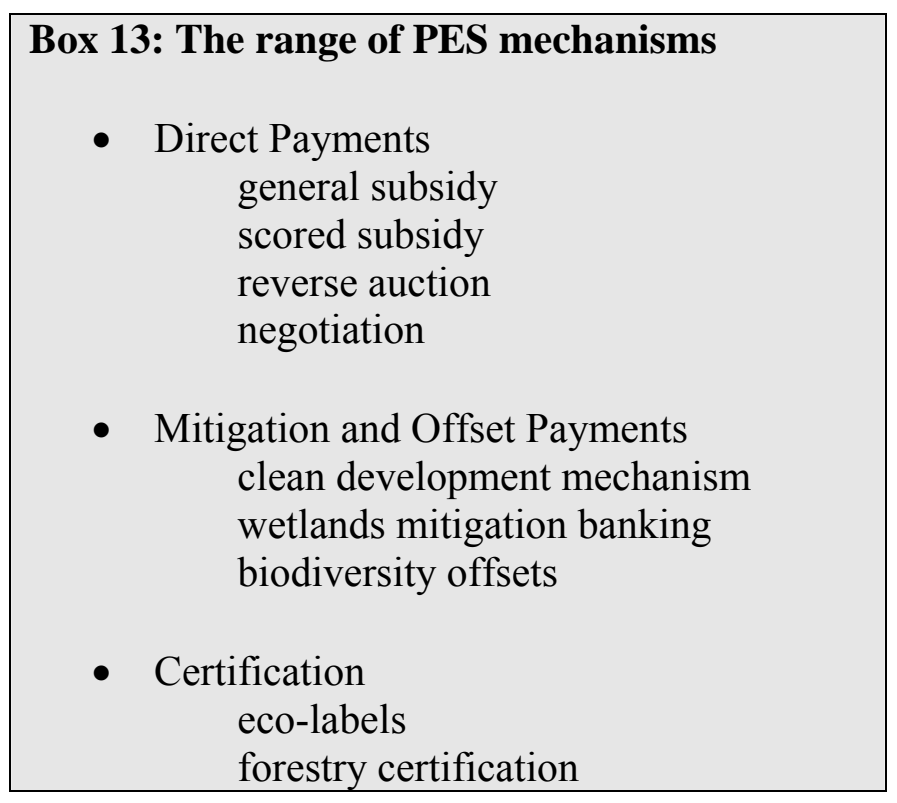

\section{i. $\quad$ Direct Payment - General Subsidy}

The simplest form of payment is a direct subsidy. Thus, for example, a government program concerned with soil erosion may provide funds for farmers to plant crops or till their lands in a manner that reduces erosion. The funding agency must determine the maximum amount each farmer can receive, the types of qualifying land use measures that will increase service provision, and then settle on the funding protocol. This may simply be on a "first come-first served" basis, with the first applicants receiving funds until the money runs out. The major benefit of this approach is low information and administrative costs. When scientific uncertainty is greatest, it may avoid errors of being too precise and guessing wrong. It may also allow for a period of experimentation to see which sort of land management changes provide the most benefit. It may also satisfy political pressure to provide a subsidy to a particular land owning interest group. The Chinese PES scheme, the Sloping Land Conversion Program, has been described as a direct payment program. Initiated in 1999, the program seeks to "restore natural ecosystems and mitigate the adverse impacts of agricultural practices carried out in previously forested areas or marginal land, which resulted in flooding, sedimentation of reservoirs, and dust storms. It pays farmers who enrol in the scheme grain seeds, 
seedlings and management expenses. The SLPC is one of the largest PES schemes worldwide: the Government has spent already over RMB 50 billion (US\$6.3 billion) which has resulted in the enrolment of over 7 million ha of cropland." (Forest Trends 2006).

General subsidies, however, may prove inefficient for they cannot meaningfully distinguish between those parties who can provide high value services and those who provide low value services. So long as the land is located in a qualifying area and the owner commits to a particular land use practice, he is eligible for a payment. Thus this approach assumes a homogeneous landscape and value of service provision, which is untrue for most services. In fact, one would expect land owners to propose changing the management of their least productive land, regardless of whether this increases or decreases the level of service provision. This creates a problem of additionality - the service would have been provided whether the land holder received PES or not.

As one survey of these schemes has concluded (Markandya et al. 2006),

The tool has however often been used as a means to transfer financial resources from richer to poorer regions, without much attention to the quantification of the costs and benefits associated with different levels of environmental services. In spite of this, it has been useful in achieving the double aim of poverty reduction and riverhead protection, thus showing positive potential in terms of integrated management of natural resources.

General subsidy payments reveal the opposite information that either side wants to know. The farmer reveals the actions he thinks will be most environmentally significant (information the government has) while the government reveals the acceptance price (which the farmer has) (Stoneham 2002). Does fencing off a particular stretch of stream provide valuable services? A flat subsidy program cannot determine this. As a result, the program is unlikely to ensure maximum value for money.

\section{ii. $\quad$ Direct Payment - Negotiation}

Another common approach involves direct negotiation with providers by either public or private parties. This approach starts with the assumption that different landholders can provide different levels of service and should be compensated accordingly. The service beneficiary sits down with the service provider and strikes a deal. This was the approach used by Perrier Vittel in France. While the transaction costs can be higher than other mechanisms, it may be preferable when there are few market participants or there are significant uncertainties over service provision or willingness to accept.

Direct negotiation has the advantage of allowing individually crafted agreements but can be labor intensive if carried out with a large number of landholders. It also lacks the mechanism of farmers competing against one another to provide services and requires the purchaser to assess accurately the landholder's willingness to accept. Perhaps most 
important, because the negotiations will likely take place in a serial fashion, it may be hard to develop a regional approach. In the context of water quality, for example, developing a subcatchment-wide strategy for service provision will be difficult if proceeding with farm-by-farm negotiation. This problem can be overcome in part by paying a third party, either local government or a specially-created funding body, rather than the landholders directly. This is the general approach followed in the New York Catskills case. While a reasonable strategy for ensuring the proper disbursement of millions of dollars, this may be too administratively burdensome for smaller scale programs.

\section{iii. $\quad$ Direct Payment - Scored Subsidy}

To address these concerns, many subsidy programs rely on scoring strategies. These use indexes or other assessment methodologies to provide scores for various attributes, whether it be presence of biodiversity or proximity to a stream. The goal is to use these scores to identify the service providers who can offer the greatest level of services. The Conservation Reserve Program in the United States, described below, takes this approach.

\section{Box 14: Conservation Reserve Program}

Created in 1985, the Conservation Reserve Program (CRP) is one of the largest ecosystem service payment scheme in the world, providing annual rental payments and sharing the cost of conservation practices on farmland. First created to address problems of soil erosion and to support farm incomes at a time of plummeting crop prices, the program has grown over the years, now paying for land changes that promote water quality and wildlife habitat, as well. Its annual payments exceed US\$1.6 billion dollars for activities on over 34 million acres. It is estimated that topsoil loss has been reduced on CRP lands by $21 \%$ and pesticide and nutrient run off greatly reduced, as well.

CRP contracts extend from 10 to 15 years. To be eligible for CRP support, the farmland must have been planted in two of the five most recent crop years and meet a set of requirements ensuring it can provide services. Farmers wishing to enroll in the CRP have their offers ranked by government field officers according to an Environmental Benefits Index. This index is a composite score, with points for:

- Wildlife habitat benefits resulting from covers on contract acreage;

- Water quality benefits from reduced erosion, runoff, and leaching;

- On-farm benefits of reduced erosion;

- Benefits that will likely endure beyond the contract period;

- Air quality benefits from reduced wind erosion; 
- Benefits of enrollment in conservation priority areas where enrollment would contribute to the improvement of identified adverse water quality, wildlife habitat, or air quality; and

- Cost.

Farmers submit a bid for their land to be accepted in the program. To increase the likelihood of their bid being accepted, farmers can stipulate that they will accept a lower rental rate than the local market price. Offers are ranked according to score and bids selected from their relative ranking. CRP offers $100 \%$ of the restoration costs and legal fees if farmers are willing to enter into permanent conservation easements.

Sources: USDA 2003

The comparison of general subsidy and scored systems is well described in the survey excerpted below (Markandya et al. 2006).

$[\mathrm{T}]$ he traditional approach for the conservation of standing forests has been to pay a flat-fee per hectare of forest to landholders, who voluntarily enroll part of their land (up to a maximum). Examples of this system can be found in Mexico and Costa Rica, Ecuador, as well as in China's Grain for Green scheme. These flatrate schemes, although easier to implement, are unlikely to be efficient - and, given the budget constraints in conservation activities, maximising the benefits per dollar spent is important. It may be preferable to design specific payment mechanisms that peg the transfer of funds not only to a land management, but also to the real value-added of forest conservation, which will vary depending on the type of trees conserved, the location of the land parcel.

While scoring systems offer advantages over general subsidies, they have downsides, as well. First, they are more expensive to administer. Second, they may not be accurate if the measures chosen as proxies for service provision are inadequate.

\section{iv. Direct Payment - Reverse Auction}

An increasingly popular means to disburse direct public PES is the use of "reverse auctions." This approach relies on landholders providing sealed bids to the government of how much they are willing to accept for changes in land use management. Those bids providing the greatest service provision at lowest cost are funded first, and so on until the funds run out. While the CRP, described above, has features of a reverse auction, the most successful example has likely been the BushTender program in Australia, described below in Box 14.

\section{Box 15: BushTender}

In Australia, the State of Victoria's Department of Natural Resources and 
Environment has developed a pilot program to conserve native vegetation remnants on private property. In exchange for payments from the state government, the landholders commit to fencing off and managing an agreed amount of their native vegetation for a set period of time.

The first BushTender trial was completed in 2002 in the north central and northeast regions of the state. With the assistance of farmers' associations, the Victorian Department of Natural Resources (NRE) publicized that it might be willing to pay farmers to conserve native vegetation. Interested landholders contacted NRE, who then sent out field staff to inspect the sites, explaining to landholders which of their native vegetation were most significant and what kinds of conservation activities would be most effective. The field staff assessed the value of each site's native vegetation on two scales of value. One scale was called the Biodiversity Significance Score (rating the site's conservation value according to scarcity of remnant types) and the other the Habitat Services Score (assessing the proposed management action's contribution to biodiversity improvement, such as fencing or weed control). Landholders were informed of the Habitat Services Score, but importantly, not the Biodiversity Significance Score. Thus they were told which land management changes were most important, but not how significant their remnants were. Interested landholders then could choose to submit bids, detailing in a management plan developed with the field officer which remnant vegetation (and how much) they would be willing to conserve, as well as the management regime they would implement for the remnants. The range of proposed management actions ranged from excluding stock, retaining large trees, and controlling rabbits, to controlling weeds and revegetation.

Because NRE had an estimate of potential biodiversity importance for each of these sites, they were able to calculate the best value for money (i.e., by identifying those bids that offered greatest biodiversity value for least cost per hectare and graphing them, as in Figure 3, below). Beyond the fact that the scheme was well received and oversubscribed, the environmental benefits seem significant. NRE field staff concluded that most of the successful bids contained sites of high or very high conservation significance, including twenty-four new populations of rare or threatened plant species.

Sources: Stoneham 2002 


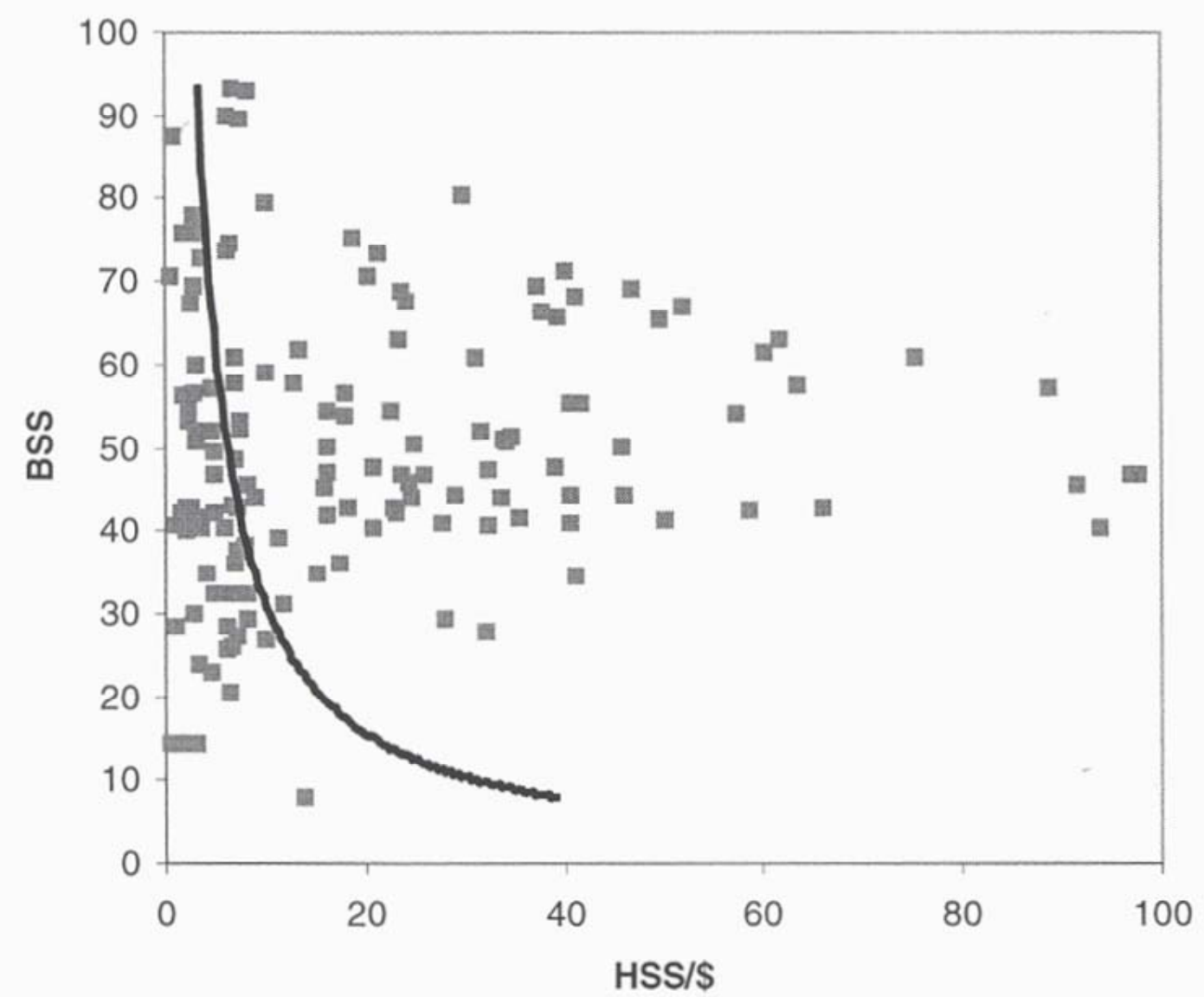

Figure 3: Graphing Biodiversity and Habitat Scores of Field Sites

The reverse auction approach has two major benefits over general subsidies. First, communication is more efficient. The program gets farmers to weigh the costs and benefits of land use changes (deciding for themselves which actions to undertake) and changes the way landholders think about the benefits their land produces. Farmers reveal to the government their willingness to accept in order to institute these changes. Through self-selection, landowners identify their opportunity cost in producing services instead of crops. The government, for its part, decides which land use changes are most effective in meeting its overall service provision goal. This stands in contrast to the information exchange described above.

Viewed through the perspective of information economics, farmers now have an incentive to "self-identify" as potentially valuable service providers. This can considerably lower the cost of information gathering. By partially privatizing a public good, payment schemes can create a mechanism to shift the costs of providing this information, but the scheme must be carefully designed, for without the landholder's information, the government is at risk of overpaying. Equally, without the government's information, the landholder has little sense of the relative value of the alternative land use or how to optimize the service provision. 
Second, this type of payment scheme effectively creates a market dynamic, where potential purchasers bid against one another for the payment. For many landholders, uncleared native vegetation is often viewed as lost income. The key to the reverse auction approach is that it requires landholders to determine their own price for setting aside or improving their native vegetation. By having to decide how much they are willing to accept in a competitive setting (because other landholders are also bidding), the landholders must consider seriously the relative values of the land in both its current and future managed states. Given a limited funding budget, only the most cost-effective bids were funded.

Moreover, reverse auctions are also well suited to a situation of monopsony, when there is only one buyer and many sellers. This is often the case with water quality, for example, when a utility seeks to change the behavior of many landowners. Based on the results of the BushTender pilot, such an approach appears to provide the ecosystem service of biodiversity from private lands in a far more cost-effective manner than general subsidies. If there are few sellers, though, there are potential problems of bidrigging through collusion.

\section{v. Mitigation and Offset Payments}

Mitigation and offset markets are based on regulations that prohibit certain behaviour. For this reason, they are sometimes called "compliance markets." Regulations also create an exemption to its prohibition if the party can offset or mitigate its harm elsewhere. If a developer builds a road that destroys wetlands, for example, it must either create wetlands elsewhere to offset or mitigate its harms or, as is more often the case, purchase "credits" from a third party who has already created wetlands for this purpose. The government plays a central role in setting the rules for these trades - what types of wetlands qualify, how many more acres of wetlands must be created than those destroyed, how one measures the trade (hectares, wetlands function, etc.). Wetlands regulations in the United States, for example, are based on the premise of "no net loss" of wetlands. If a hectare of wetlands are filled for development, then this harm must be mitigated by the creation of a hectare or more of wetlands somewhere else. Only when the mitigation requirements have been satisfied may a permit for wetlands development be issued.

\section{Box 16: Wetlands Mitigation Banking}

On its face, the primary U.S. law conserving wetlands, the Clean Water Act (CWA), seems to prevent the filling of most wetlands. The CWA provides a limited exception, however, through a permit system for many routine land development activities before they can proceed. When applying for a permit, a developer must convince the government that no reasonable alternatives exist to the development of the wetlands, that the design of the development minimizes harm to the wetlands, and, if these two conditions have been satisfied, that other wetlands have been restored to compensate for the wetlands destroyed (known as "compensatory mitigation"). 
The government has traditionally preferred on-site to off-site locations for compensatory mitigation activities. Over time, however, compensatory activities have been allwed to move from on-site to off-site mitigation, opening the door for wetlands mitigation banking. This program allows a developer who has created a wetlands "bank" somewhere else in advance of development to draw from the resulting bank of mitigation "credits" as the development is implemented and wetlands are filled. Wetland mitigation banking now resembles a commodity market, with wetlands banks offering for sale finished off-site wetlands as "credits" to anyone who is in need of mitigation for their development permits. There were between 370 and 400 such commercial mitigation banks operating in the United States as of January 2000.

Source: Salzman and Ruhl 2001

A similar, though smaller, market exists for biodiversity offsets. In exchange for permission to develop in a species habitat, the developer must mitigate the harm by restoring species habitat elsewhere. As described below, some mitigation markets are voluntary, with companies choosing to restore habitat on their own. The challenge for such markets lies in comparability. Unlike a molecule of carbon dioxide, which is the same no matter where emitted or sequestered in the world, biodiversity is heterogeneous and location-specific, making trades difficult.

Offset markets operate in a similar manner with pollutants. In the context of climate change, for example, some regulatory markets permit those emitting greenhouse gases to offset their emissions by purchasing credits for sequestered carbon. Because planting trees can remove carbon dioxide from the atmosphere, the market designers assume that a ton of sequestered carbon dioxide is equivalent to a ton of reduced carbon dioxide emissions. The Kyoto Protocol, for example, created the Clean Development Mechanism. This provides for reduction credits from carbon sequestered by land management. Negotiations are currently underway for the next climate treaty, and many believe that a similar offset provision, known as REDD (Reduced Emissions from Deforestation and Forest Degradation), will be included in the final draft. In simple terms, REDD would pay countries for reducing emissions that would have occurred if deforestation had continued at its historic rates. REDD thus provides payments for improving the ecosystem service of carbon sequestration. Voluntary markets - carbon trades that operate outside the Kyoto framework and national laws-have also been on the rise, primarily driven by corporate social responsibility concerns (Ecosystem Marketplace 2009)

The global carbon credit market is large and growing, worth billions of dollars a year. It should be noted, however, that only a small percentage of the credits have been generated by carbon sequestration through land use change. Most credits to date have been produced by manufacturing design changes or destruction of compounds with high 
global-warming potential. The EU's Emissions Trading System, for example, does not allow sales of credits from land use (Wara 2007; Forest Trends 2006).

It should be noted that constructing smoothly functioning offset and mitigation markets is not simple. There must be a sufficient and well-defined marketplace and a community of market participants. There also must be a refined currency of trade, one that is fungible and reflects the desired environmental quality. For example, it would be a stretch to consider allowing coastal developers in one state to "trade" wetland values they eliminate for reductions in phosphorous emissions in another state. But where the environmental quality can be captured in a measurable unit (whether that be tons of pollutant or hectares of habitat) and market service areas and participants are welldefined, trading programs have had demonstrable success in a variety of contexts, increasing the efficiency and flexibility of prescriptive instruments.

Mitigation markets present a further special concern. In most markets, the buyer ensures quality. Consider when you buy a bike. If, in your first ride on the bike, you immediately find that the brakes do not work or that the seat slips out of place, you will be quick to return it to the store for a refund. In a wetlands mitigation market, by contrast, the buyer does not care about the quality of the mitigated wetland. All the developer wants is a permit to build a development. The cheaper the developer can obtain the permit, the better. Nor does the seller (the company that created the mitigation wetlands) care about the quality of the mitigated wetland, so long as the government regulator will approve the transaction. As a result, it falls on the regulator, who does not have a stake in the transaction, to ensure quality. In the case of wetlands mitigation in the United States, the government has had a poor record in this regard.

One faces a similar challenge in offset markets. So long as credit is given by the regulator for credits from land use changes, neither the seller (the land owner) nor the buyer (the company that requires the emission permits) cares whether the reductions are real or not. It falls entirely on the regulator to ensure that the land use changes are legitimate. Thus adequate governance and oversight are essential to effective offset and mitigation markets. For this reason, most compliance markets operate in developed countries, particularly the United States and Australia, rather than in developing countries that have weaker administrative, legal, and enforcement infrastructure.

\section{vi. $\quad$ Certification}

Growing in importance since the 1990s, certification schemes focus on the importance of consumption in degrading ecosystem services. As noted above, lack of information is a significant barrier to environmental protection. Consumers and corporations that wish to promote environmentally-responsible practices through their purchasing behavior cannot do so unless they have information on the attributes of the products they wish to buy or the behavior of their suppliers. Certification and eco-labels attempt to provide this information. The premise of these programs is that an important percentage of consumers and companies will prefer to purchase goods and services that are environmentally preferable if there is a reliable means of identifying them and this, in turn, will provide these goods and services a competitive advantage in the marketplace. 
To address this information need, eco-labels and certification schemes have grown rapidly over the past two decades across a range of sectors, including sustainably harvested timber, coffee, fisheries, agriculture, and even financial companies and eco-tourism. These certification initiatives' goal is to provide consumers with an objective basis for selecting environmentally responsible products, much as traditional eco-labeling programs have sought to achieve.

\section{Box 17: Forest Stewardship Certification (FSC)}

Founded in 1993, the FSC has created a mechanism to set standards, certify and label forest products that have been managed in an environmentally, socially and economically sustainable manner. FSC certification is voluntary. Forest owners who wish to use the FSC label in marketing their products must satisfy the relevant FSC standards developed for particular types of forests and conditions. Common principles include compliance with laws, clear tenure and use rights, recognition and respect for indigenous rights to the forest, etc. Compliance is certified by an FSCaccredited body that audits and then approves individual forest management.

Because timber is a global market, chain-of-custody becomes important. It is necessary to ensure that FSC-certified timber can be tracked throughout the supply chain from harvest to point of sale. This is accomplished through Chain of Custody certification, a system that ensures controls are in place to track certified wood products throughout the supply chain. Importantly, FSC does not, itself, conduct any certification activities of forest management or the supply chain. These are conducted by accredited certification organizations (currently twelve around the globe). The forest product producers are responsible for the certification costs.

As of December 2008, roughly 107 million hectares of forest in 78 countries were FSC-certified. Approximately 12,000 FSC Chain of Custody certificates have been issued in 81 countries.

Source: Forest Stewardship Council 2009

While less appreciated, the most significant market development has taken place through major wholesale buyers. Thus rather than persuading individual consumers to "buy green," much change has been driven by major suppliers such as Wal-mart, professionals such as architects and builders who purchase for major projects, and government procurement policies (Salzman 1997a).

\section{E. Payment Timing}

In structuring payments for ecosystem services, an important question concerns the timing of payments. Should they be spaced evenly, back-loaded, or front-loaded? In 
traditional crop contracts, payments are often back-loaded - payment upon delivery of goods. Since services are delivered continuously, though, evenly-spaced payments seem appropriate. If there are considerable up front costs, such as building dams, swales or fences, front-loaded payments may be necessary. But, in the case of failure to perform, front-loaded payments weaken the potential sanction of stopped payments. In the BushTender scheme in Australia, for example, initial payments were made to cover capital costs, with annual progress payments that followed.

Payments could also be conditioned on meeting certain milestones - a certain amount at the signing of the contract, a certain amount when non-native vegetation has been cleared, a certain amount when fences have been installed, etc. This has the disadvantage of greater administrative costs but does offer the advantages both of close progress monitoring and meaningful incentives to meet the next milestone, particularly in poor areas where the milestone payments may be significant parts of a family's income.

\section{F. Payment Type}

In most cases, PES takes the form of monetary payments, but that need not be the case. In a PES watershed project in Los Negros, Bolivia, for example, the payments are not in cash. Rather, the participating communities are paid in-kind, with bee boxes, technical training and barbed wire. The project designers found that these benefits were considered more appropriate than cash because the payment was to a community rather than individuals, because the bee boxes and barbed wire were valued by the community, and because honey production was regarded as a long-term economic opportunity. (Asquith 2007) In-kind payments also provide a clear visual symbol of the potential added value that PES can provide. One could also imagine payment in the form of cashvalue vouchers or dedicated vouchers (only valid for use in purchasing agricultural goods, for example).

One potential downside to payments of infrastructure (such as building roads) or goods (such as beehives) is that these are hard to take back. Unlike periodic cash payments which can end if the provider breaches the agreement, taking back a road or even beehives is less obvious. Thus the use of non-monetary payments can, depending on the context, weaken potential sanctions in the event of noncompliance.

\section{G. Risk Allocation}

The heart of a PES agreement is contained in the terms setting out the respective rights and obligations of the seller and buyer. Here are contained the specific actions that either party must take to fulfill the agreement. First, the agreement must make clear what is expected of the seller (or, more accurately, the provider of watershed services). This can take two basic forms. The obligation can be stated as an input or as an output. In an ideal world, one would condition payment on the value of service unit delivered (seller outputs) rather than up-front costs in fencing or weed control (seller inputs). In broad policy terms, the choice is between design or performance payments. You get paid for what you put in versus what you produce. 
Output payments might take the form of litres of water transpired per day, nutrient uptake per year, percentage improvement in water quality, etc. This is much closer to how farmers are paid for other cash crops, whether it be liters of milk or bushels of carrots. Theoretically, payments based on actual service provision would be preferable since it is what the buyer ultimately cares about. Such an approach, however, is rare in actual PES schemes.

In practice, PES schemes favour the interests of the sellers and tend to be based on inputs, in particular, on particular land use activities. Thus with water deals, the payment is based on installing riparian fencing, planting trees, preserving standing forests, or some other land use activity, rather than a specific improvement in water quality or stream flow. The assumption is that this input will result in the desired service output.

Viewed broadly, however, this arrangement really is about risk allocation. The buyer is accepting the risk that requiring inputs (land management activities) is a sufficiently close proxy to service provision that the payments are justified. So long as the landowners manage their property in accordance with the terms of the contract, they are paid whether adequate services are provided or not. Parties to these transactions must therefore hope that the land management requirements are accurate proxies for service provision. It should be noted that for some services this seems perfectly fair.

A second aspect of risk allocation concerns innocent loss. A farmer may be willing to sign a PES contract for water purification if it requires specific land management changes such as planting and maintaining a riparian buffer. Presumably clean water will be harder to provide after a major rainfall, as nutrients and soil are swept into watercourses. But the rainfall is beyond the farmer's control. Of course, it is beyond the control of the seller, as well, so the question is which party should bear the risk of such events. In water service contracts, the buyer tends to bear these risks. In carbon contracts, the issue is sometimes known as permanence and is much more complicated. The problem is obvious - who bears the risk if a forest fire burns down trees that were sequestering carbon?-but there are many solutions in practice, ranging from simple allocation of risk to posting bonds or insurance policies. One could also rely on a form of self-insurance, with the provider ensuring extra service provision, such as planting more trees than necessary for carbon offsets or fencing off additional riparian areas to prevent erosion, just in case there is an unexpected loss.

\section{DESIGN CHALLENGES TO EFFECTIVE PES PROGRAMS}

In fact, there are two levels of design to consider in crafting PES. Once one has addressed the fundamental issues - which service to provide, the buyers and sellers, the level of service needed, the payment mechanism, when payments take place and what form the payments take-designers need to consider second order issues. These turn on how to manage the challenges to PES effectiveness, and range from property rights and

supporting institutions to perverse incentives. While coming after the first order considerations, these issues are extremely important, indeed critical, to the success of a 
PES scheme. The next sections explore the PES design issues raised by modeling and monitoring, property rights, perverse incentives, supporting institutions, and poverty alleviation.

\section{A. Modeling and Monitoring - Can you measure what matters?}

While an obvious assumption in PES schemes, it is worth emphasizing that the buyers need assurances that the payments they have made will, in fact, lead to the service provision they desire. No one likes to pay something and receive nothing. To gain this assurance requires both adequate modeling and monitoring. Effective modeling shows the biophysical pathway of service provision, identifying metrics that should be monitored in order to assess service provision (such as a farm's proximity to a watercourse, its slope, etc.). Effective monitoring serves two purposes. First, it creates a baseline. One cannot determine if there has been a change in service provision unless one first establishes a baseline to compare against. This is a fundamental issue in the "additionality" debate over the role of forests in carbon markets. Second, monitoring provides the data to assess compliance and service provision once performance has begun.

Monitoring is easier in certain cases than others. Thus, PES schemes based on inputs are easier to monitor than those based on outputs. If one is mandating or paying for specific land use practices or changes, such as in the MRFF or Perrier Vittel schemes, compliance monitoring need only examine the land management change. The buyer simply visits the piece of land and checks if the fences have been properly constructed in the right place, for example, or the correct number of trees has been planted. Once one moves from services such as carbon sequestration, where relatively simple relationships can be estimated between ground vegetation and carbon sequestered, it becomes both difficult and costly to measure actual provision from a specific landowner of services such as water purification, pollination, or flood control. Equally, as the MRFF case study demonstrated, certain services are easier to model than others.

From this perspective, it becomes clear that the real success of BushTender does not lie in its use of reverse auction mechanisms. That is an efficiency improvement that reduces the cost of service payments. The key to its success lies in the field scoring system. The government field officers were trained in an effective procedure and given a scoring sheet so that their estimates of service provision proved credible. If, on the other hand, the assessment of biodiversity value proves to be poor, then there is no assurance that the money has been well spent nor that the public is actually getting value for money. BushTender's designers felt it could provide accurate assessments of biodiversity value through field visits to specific patches of remnant vegetation.

Doing so for other services, such as addressing salinity in the water table through

planting trees (i.e., lowering saline groundwater through the service of evapotranspiration), has proven far more complicated. In many catchments, for example, the groundwater hydrology is not uniform, sometimes operating at a small scale with recharge and discharge on the same properties and sometimes operating throughout an entire subcatchment. Unless there is a clear understanding of the local hydrology, one 
cannot expect payments for services for the simple reason that people downstream will not know what they are paying for. Nor can one reasonably set taxes or establish regulations with any certainty that the desired behavior will result in meaningful service provision. Over time, such uncertainties may be overcome by better modeling and monitoring technologies. But, at the moment, they confound setting up a market or other policy instruments.

That is the main reason Macquarie River Fruit (MRFF) and Fibre did not continue its reforestation pilot with NSW State Forests in Australia. Beyond public relations benefits, MRFF had no idea if it was getting value for the money it had paid to plant trees in the upper catchment. The local hydrology was too complicated to model accurately. This is a real problem. As a Forest Trends report observed (Forest Trends 2006),

Most public PES systems, when initially set up, have had quite inefficient targeting of funds, in that many payments went to landowners or land uses that actually did not produce the desired ecosystem services. Mexico's hydrological payments program, China's Sloping Land Conversion Program, and Costa Rica's payments for reforestation that inadvertently reduced water flow have all run into limitations due to program targeting and design issues.

In addressing this challenge, PES designers face a trade-off. To take the salinity example, at one end of the spectrum salinity models have been developed that provide robust estimates of service capacity per hectare based on topography, deep drainage, and runoff under different land uses. This is expensive and time consuming. At the other end, one could rely on "rough and ready" field estimates based on visual observation and scoring. BushTender used this approach in valuing biodiversity and perhaps basic rules of thumb could be developed for water quality, as well (such as proximity to watercourse, slope of land, extent of riparian vegetation, etc.). Whatever the method used, it must be able to take into account spatial variation and landscape context, reflecting the fact that some sites are more important to water quality than others, but not so expensive that transaction costs swamp the efficiency benefits of markets.

This is an important point. PES schemes work best with the rules are simple and compliance monitoring mechanisms remain inexpensive. Yet this may result in less information than buyers demand or need. In general, the more accurate the monitoring and modeling, the better buyers understand whether land use changes will improve service provision but, equally, the more expensive the transaction.

The net result is that it will be easier to develop markets for some services than for others, for the simple reason that those buying services will be more confident that they are receiving value for their money. How difficult, for example, is linking the contributions of individual land management decisions to water quality in a water supplier's subcatchment? Is this determination more similar to assessments of biodiversity or to salinity control? The success of an ecosystem services approach for water quality depends critically on the accuracy and cost of such assessments and, by extension, the creation of assessment methodologies for use in the field. 


\section{B. Property rights - Does the seller control the service?}

Since payment is generally premised on specific land use activities, the other basic obligation of the provider is to demonstrate sufficient ownership or control of the land to ensure service provision. The buyers need to know whom to pay and have some assurance that they can undertake the land management or service provision they have agreed to. In broad terms, this is an issue of property rights, but there are many different types of property rights. These include the right to occupy, the right to use, the right to derive income, the right to sell, and the right to exclude, among others. Obviously, depending on the circumstances, some of these rights will be more important for service provision than others.

Direct buyer-seller deals require adequate contract law and legal services from the government to provide contract enforcement and, ideally, clear legal guidelines as to who "owns" ecosystem services and who has the right to sell them. For example, some countries have claimed carbon rights for the state, so that private sellers cannot receive payment without government authorization.

In an ideal situation, the provider would hold all of these property rights and could easily prove ownership of the land. This is often the case in OECD nations. In much of the world, however, this can prove a major challenge. In Latin America, for example, land title processes are often incomplete. In rural areas, many landowners have not registered their deeds, or may not even have deeds. Thus notarized deeds of sale, land titles, and properties in full compliance with the law can be hard to find in certain regions. Long-time inhabitants of public lands in some countries may not even know they live on public lands. In some countries, such as China, where most natural resources are owned by the State, it may prove difficult to assign clear rights and responsibilities to individual resource users (IUCN 2009).

Supporting institutions are particularly important in the context of property rights. In a developed system, owners need a land registry to record their title and where buyers can search titles, there must be adequate contract law and legal institutions to adjudicate disputes, and adequate authorities to enforce judgments. These supporting institutions, however, are not always present, particularly in parts of some developing countries. This does not, however, mean that PES schemes cannot successfully operate there.

Because clear title is not always available and the cost of establishing clear title may not be justified by the size of the service payments, PES schemes must often consider both de jure and de facto legal title. De jure title describes the legally recognized ownership status. De facto describes the actual practice on the ground. Individuals or communities may effectively control land so that service provision can be ensured yet not have clear legal title. Those on the land may even be squatters. In such a case, de jure status may be more important than de facto status. This is particularly significant when supporting institutions (described below in Section D) such as government monitoring and enforcement are weak. Indeed, in some cases service payments are particularly attractive because they are seen as a way to legitimize unclear land title by giving the land manager greater credibility (IUCN 2009). 


\section{Perverse Incentives}

Turning back to the watershed example in Figure 1, you will recall that farmers graze cows on their fields beside the stream that flows into the drinking water reservoir. The farmers could manage their land to provide an improved service of water purification by planting riparian vegetation buffers (i.e., erecting fences to protect strips of plants alongside the stream from grazing). Such vegetative buffers capture nutrients and reduce silt before they reach the watercourse. Water consumers downstream benefit from these actions when drinking clean water that does not require extensive pre-treatment. The PES scheme created an incentive for farmers to put in riparian fencing because they can now capture the positive externalities of the water purification services provided to downstream water drinkers.

If one enquires more closely, though, paying for these services suggests a number of tensions. To start with, those farmers who have already put in riparian fencing no longer have a significant potential for increased service provision and, as a result, are unlikely to be paid. Should every landholder who provides environmental services be paid? Given a finite budget, the answer to this would seemingly have to be "no." It is hard to imagine a practical scheme, for example, that pays everyone whose vegetation reduces nutrient flow in the watershed. If one seeks to pay for discrete cases of ecosystem service provision, clearly some land uses are more important than others. But how should one decide who gets paid and who does not?

As noted earlier, some PES schemes pay landholders for maintaining the status quo, e.g., to keep their upper watershed lands forested. These are conservation payments not to change the land use, and instead to maintain current practices. In the case of the hypothetical above, payments are made for changing land use practice. In significant contrast to the first example, though, some of those being paid in many respects also are causing the problems. For example, because some farmers have not built sufficient infrastructure or established riparian vegetation, their cows are discharging significant nutrient loads into streams. They are effectively being paid to clean up their cows' manure.

To frame this dilemma more generally, consider which landholders should be supported by ecosystem service payments - those who currently provide services or those whose properties pose the greatest nutrient or sediment problems (and hence the greatest potential for increased service provision)? This decision will be a challenge for many service markets. To frame this dilemma more starkly, imagine two adjacent farmers in the landscape of Figure 1, Farmer A and Farmer B, who raise cows for a dairy operation on gently rolling land beside a stream that flows into a reservoir. Concerned over streambank erosion, five years ago Farmer A constructed fencing alongside his stream, creating a ten-foot riparian buffer on either side of the bank. This change in land management has significantly reduced the amount of nutrients and soil washing off her land and, consequently, has reduced the eutrophication and turbidity downstream. Farmer B, by contrast, has continued to manage his land much the same way as his predecessors, with nutrient and soil runoff after large storm events affecting water quality 
in the downstream reservoir. Should the water supplier be willing to make ecosystem service payments to address eutrophication and turbidity control? If so, which farmer should receive payments, and how much?

At first glance, one might think PES payments should be directed toward Farmer A because he provides the greatest level of service provision. While seemingly obvious, this assumption may turn out to be misguided if we care about efficiency. If we want to increase service provision, then paying Farmer B to improve his property through riparian fencing makes good sense. This will reduce pollution loading in the reservoir. But how can this be described as an ecosystem services payment scheme? On its face, this seems to be paying more for the lack of ecosystem services. That is, Farmer A is already providing services but will receive less than Farmer B, who currently provides few.

The key point to recognize is that one is not really paying for ecosystem services but, rather, for improvements in service provision. Farmer B likely has much greater potential for increased service provision because his current level is so low. Farmer A has little potential increase because he has already put in riparian fencing. Farmer B, by contrast, could greatly increase the service of water purification by now putting in fencing.

If the goal is improved water quality, PES designers should value most those actions that most improve the water quality on the margins, and those will primarily be actions taken from today that improve the status quo. Through this view, then, the PES scheme should pay more initially to the Farmer B's of the world who change their land use than to the Farmer A's who have already made the improvements, for the simple reason that the actions of Farmer B will lead to greater marginal improvements.

This approach, however, may pose a problem known as a "moral hazard." If we say people are being paid to provide a service, then how can PES schemes ignore those who already provide it? What kind of message does that send? Is it not essentially paying off the bad actors and thereby encouraging undesirable behavior? More generally, how do PES schemes equitably account for the baseline that is already out there? Those farmers who have already made the investments and managed their land responsibly may not receive any payments. Only those who have been less responsible will benefit, the argument goes, creating a disincentive to land stewardship.

Critics of the Conservation Reserve Program have made this very point, arguing that the program can send the wrong message. As one scholar has written, many farmers have been frustrated because "they had taken too good care of their land and could not qualify [for CRP funds], even though their land was intrinsically as erodible as their neighbor's" (Salzman 2000). The danger is that responsible land managers can become dispirited if those who employ less responsible land management practices effectively are paid for doing so. Sven Wunder makes a similar point (Wunder 2005). 
being a so-called 'ES provider' often just means not being an environmental vandal. Across-the-board entitlements could endorse blackmail by anybody owning a nonthreatened asset, from Scandinavian forest owners threatening to cut down their trees to receive carbon payments, to remote indigenous people threatening to deliberately pollute a river to receive watershed payments from downstream users. It is crucial that the underlying 'victim pays principle' in PES should not be taken to such absurd extremes.

Other concerns have been raised over the problems of holdouts and free riders. These are most easily seen in the context of biodiversity conservation. The functional value of a reserve design or wildlife corridor depends critically on contiguous parcels. If successful, the benefits from the sum of connected land parcels managed for biodiversity conservation should be greater than its parts. This can be frustrated, though, by the actions of a very small number of landholders who can hold out for prices well above market rates. Without their participation, it may be impossible to create effective habitats. Moreover, neighbors of those who dedicate their lands to biodiversity conservation may choose not to conserve biodiversity on their own land but, instead, free ride on the wildlife amenities on adjacent land. Given these two obstacles to competitive markets, one can understand the calls for coercive instruments.

Holdouts and free riders are likely much less of a concern in the context of water purification services because the effectiveness of landscape management, for example, is less likely to turn on the actions of a handful of landholders. To guard against holdouts, BushTender and the CRP rely on reverse auctions - where farmers bid against one another to provide the lowest price for the government to choose. So long as the reverse auction is competitive and there are a sufficient number of farmers involved, holdouts and collusion become less likely.

It turns out that the threat of holdouts is much more significant in the context of biodiversity than in water quality. If a farmer is paid to fence off a stretch of native vegetation and, when payments cease, allows cattle to roam through and graze, then most of the benefits of biodiversity conservation may be lost, as the available habitat for an endangered population becomes scarcer and extortion becomes more likely. With water quality, in contrast, the benefits from the service of water purification have been enjoyed throughout the contract, and if the services are not received from one farm, hopefully a comparable level of service or better can be received from another. Moreover, changing the land use to discourage biodiversity (such as mowing the lawn) imposes fewer costs on the farmer than removing riparian fencing that may lead to soil loss from erosion or loss of stream banks.

\section{Good Governance}

The term "governance" refers to the particular aspects of how decisions are carried out and implemented. Even the best-designed agencies and programs can fall short if they do not take into account the many aspects of good governance. At its broadest, good governance constrains government to prevent the abuse of public power 
and, equally, constrains private actors to prevent market abuse. In general, the fundamental aspects of good governance include openness, transparency, public participation, accountability, the rule of law, predictability, and timeliness. Thus good governance refers not only to governmental activity but to private actors, as well. Good governance is particularly important in the context of local PES schemes, such as watershed PES, because trust is so fundamental to the programs' long-term success. The following paragraphs assess specific aspects of good governance.

\section{i. $\quad$ Public Participation}

Public participation ensures not only that the relevant stakeholders are involved but feel they have meaningfully participated in decisions - that their concerns have been heard. Broad participation provides decisionmakers important information about the needs and concerns of relevant stakeholders and may also inject new, creative ideas into the program design. Moreover, stakeholders are more likely to support decisions in which they feel vested.

This is most evident in watershed PES during the initial scoping and negotiations. Watershed PES advocates need not only to identify potential buyers and sellers but, more fundamentally, persuade the broader range of stakeholders why PES transactions will provide positive benefits. This is particularly important when local communities are involved rather than individual land owners. The key decisions involve:

(1) How to engage the public (closed meetings or open public meetings)

(2) Which public to engage (individual stakeholders, broad groups, or creation of special groups created specifically for the watershed PES)

(3) How long to engage the public (meetings held over how long a period of time)

In the Bolivian pilot project in the Los Negros-Santa Rosa, for example, Fundación NATURA conducted a series of negotiations and public campaigns to engage the potential participation of ecosystem services buyers and sellers. Similarly in Brazil, the Proambiente program evolved after several years of public discussion, commencing with rural social movements from in Amazon region and eventually rising to the level of a federal policy. Or consider the Water Steward Programme of Extrema in Brazil's Minas Gerais State (IUCN 2009).

it took two years of negotiations between project developers from the city government and the local communities to convince them that the programme would bring benefits to the entire population. Project developers treated the community engagement phase with great care to ensure the approval and participation of local residents. The programme took 10 years of negotiation and restructuring to be enacted.

PES designers must also take into account the cost from ensuring public participation both in terms of resources and time. Economists refer to this generally as 
collective action problems. The more interests involved in a decision, the more costly the decisionmaking process. The relative costs and benefits of greater versus more restricted public participation will depend on particular settings. Nonetheless, explicit consideration of these issues, regardless of the particular choices made, will help ensure that the key stakeholders are not simply overlooked - an important point later on once the programs are underway and potential critics arise.

\section{ii. $\quad$ Transparency and Access to Information}

Transparency and access to information are essential to good governance both because they build trust and ensure decisions will be made in an open manner. Transparent processes reveal not only the decisionmaking process but the information in the process, as well. In some countries, legislation specifically provides both for transparent decisionmaking and access to information. This varies fro country to country both in legal terms and practice.

One can find many examples of both transparency and access to information in Latin American watershed PES projects. In Bolivia's Los Negros project, for example, periodic workshops at both the local and national level since 2004 have regularly brought together project developers, local and national authorities, and other interested institutions. The workshops share information on experiences and lessons learned to date. Brazil's Project Oasis and Extrema Water Steward Programme have relied on websites to post and share information, also providing contact details for those interested in obtaining more information (IUCN 2009).

\section{iii. Accountability and the Rule of Law}

Parties entering into PES watershed agreements need to be confident that terms of the agreement will be respected and, in case they are not, that their interests will be supported. Put simply, they need to know that when they make a deal with someone, the commitments made by all parties will be respected. In dealing with government-funded programs, for example, this means that private parties will be protected from arbitrary decisions, that the influences of corruption, nepotism, and capture by special interest groups will not lead to unjust implementation of the agreement or unfair application of the agreement's specific terms. Without such reliability and predictability, parties will be less likely to enter into agreements in the first place.

It is worth noting that, while legally binding contracts may appear to provide greater assurances of accountability than oral or memoranda of agreement, that is not necessarily the case. In some settings, particularly in local watersheds where custom and norms may have as great, if not greater, influence than laws on the books, agreements other than contracts may effectively have the force of law.

\section{iv. Remedies and Dispute Settlement}


The importance of monitoring has been discussed above. If monitoring uncovers noncompliance, it is important to set out in the PES agreement either the potential consequences or the procedure to determine the appropriate consequences. Without an adequate deterrent, noncompliance may be more likely. Determining the nature of the deterrent, though, requires careful consideration. Assume, for example, that a farmer signs a five year contract to maintain riparian fencing and does not build the fence, or tears it up after four years. Compliance monitoring, which must occur at periodic intervals to ensure credibility, uncovers these breaches six months after they have occurred. What should happen?

It seems clear that future payments should certainly stop. This becomes complicated, however, in the case of in-kind payments such as education or health facilities. And what about payments made prior to the breach? Presumably, if services were provided up to a certain date, then payments for those services were legitimate. If, however, the payments have been front-loaded then some form of restitution seems appropriate. As a further disincentive to breach, one might also consider penalty clauses. Often found in construction contracts, these clauses provide for penalty payments if certain requirements (such as completion date) are not met. If such clauses are not commonly used, however, they may send an antagonistic signal to landowners.

PES agreements include a wide range of remedies. Brazil's Project Oasis contract, for example, contains specific text addressing non-compliance. If the monitoring report provides instances of noncompliance, landowners have 3-15 days to respond. The O Boticário Foundation specifies the length of time available in each case. By contrast, the Bolivian pilot program in Santa Rosa does not contain any provisions on non-compliance or dispute resolution in the contract, focusing on keeping the agreement simple. In practice, the participating families took their concerns to their local association and to the program representatives during meetings held periodically (IUCN 2009).

Depending on the setting, weak penalties can prove very effective within particular social contexts. The importance of community cohesion can make exclusion of the non-complying party from the PES scheme very effective in a project operating at a small scale within a cohesive community. As a report on Bolivian watershed PES schemes explains (IUCN 2009),

Under these circumstances, trust between the parties plays a major role, and social pressure and the fear of suffering from social rejection can motivate parties to comply with any obligation emerging either from a contract or from social rules. This is why the simple exclusion from the project has been considered a sufficient penalty until now.

As contracting parties become more sophisticated, remedy provisions generally take on more detail. These agreements tend to include explicit conflict resolution clauses, sometimes calling for arbitration to settle disputes, as well as more detailed schedules of penalties for noncompliance. 
In this context, one must keep in mind the central importance of transaction costs. In programs where the payments are fairly small, it simply will not be worth the cost to go through elaborate dispute resolution procedures for noncompliance. The sums involved do not justify the transaction costs. Thus informal processes may prove more appropriate.

\section{E. Supporting Institutions}

Very few transactions take place in the absence of supporting institutions. Even the simplest contracts between buyer and seller, for example, rely on institutions to adjudicate disputes when they arise and enforcement to ensure the judgments are carried out. A range of specialized institutions, both public and private, can promote PES transactions.

Consider, for example, the role of institutions in the case of payments for carbon sequestration. To facilitate exchange of carbon sequestration credits, the Australian state of New South Wales has statutorily created an alienable property right in sequestered carbon. Thus a forest landowner can sell credits for carbon stored in his trees, and this can then be sold again by third parties. Carbon registries have been created, as well, to record obligations and credits. In the United States, the Chicago Climate Exchange provides a marketplace for buyers and sellers of carbon credits to exchange with one another. A number of countries have created the equivalent of a national carbon office that keeps track of carbon emissions and reduction projects. And private certification organizations now provide the service of certifying that carbon sequestration projects accurately report on their activities.

An IUCN report on PES design provides a useful summary of the many roles intermediary institutions can play (IUCN 2006).

Intermediaries are often essential catalysts in setting up and running payment schemes. They act as an honest broker between service buyers and sellers to improve the process of negotiation. They help to define contractual terms, fill institutional gaps and facilitate financial transactions. These roles can be vital and result in lower transaction costs and increased trust and transparency. Intermediaries are commonly local NGOs, community groups or government agencies who are funded or subsidised by donor organizations. Intermediaries often act in effect as administrators for a scheme.

An effective intermediary seeks to maximize downstream service buyers' demand by identifying sellers who will deliver the greatest improvement in services at the lowest cost. This is not straightforward and is almost certain to vary by location. The principle should hold unless other political, social or environmental criteria are imposed or included in the goals of the scheme.... 
An effective intermediary should try to concentrate on facilitating negotiations and administration of the scheme, delegating technical functions to specialists. Assistance can be provided with feasibility studies, communication and exchange of information, forest management plans, and monitoring, including collection and management of hydrological data. Specialist support is also often used to support participation by landholders. For example, FONAFIFO in Costa Rica administers the national PES (Payment for Environmental Services) programme, but delegates monitor and liaise at the local level with local groups such as FUNDECOR. These local groups are in direct contact with local farmers, helping to prepare applications for payments.

As described above, there are many different types of institutions that can support PES and, importantly, these need not be formal, government bodies. Indeed in many parts of the world formal institutions are ineffective and parties cannot assume that laws will be complied with or enforced. In such cases, informal local institutions based on customary practices can provide the support needed for PES schemes to operate.

In many rural communities in developing countries, for example, land tenure and property rights are not formally established. If a community or its members cannot document their control or ownership of the relevant landscape, structuring a transaction can prove difficult. Nonetheless, customary rules of land tenure may prove sufficient assurance for the PES scheme to work. This is an example where de facto rights are as important as de jure rights, if not more so.

\section{F. Poverty Alleviation}

Some reports on PES schemes have explicitly called for greater attention to the role they can play in poverty alleviation. The IUCN report, for example, states that

When developing a payment scheme for watershed services, there should be explicit goals relating to social equity that lead to assessment of the social impacts of the scheme and its implications for poverty reduction (IUCN 2006).

If policy makers choose to use PES schemes for dual purposes - both provision of ecosystem services and poverty alleviation - they need to consider carefully the tradeoffs involved. Importantly, depending on local circumstances and their design, PES schemes do not necessarily improve poverty alleviation goals and potentially could worsen the situation (Pagiola et al. 2003).

PES schemes offer a number of clear potential benefits for local communities. The payments can provide important additional revenue for basic needs. Importantly, these payments may not need to be large to make a real difference so long as they constitute a large percentage of the household income. As one studied found (Wunder 2005; Miranda et al. 2003), 
In Costa Rica, PES payments accounted for more than $10 \%$ of family income in more than one quarter of participants; in Virilla PES payments averaged $16 \%$ of cash household incomes...[In] poverty-struck zones the situation can be quite different. In Costa Rica's Oca Peninsula, a small survey found that of PES recipients that were under the poverty line, the scheme lifted half above it and became the primary household cash income source in $44 \%$ of cases. In Pimampiro (Ecuador), watershed-protection payments to poor upland colonos made up 30\% of recipient households' spending on food, medicine and schooling.

These payments can be particularly important in communities with limited revenue streams that are also intermittent. This is often the case in farming communities dependent on a small number of cash crops. If the PES scheme is well administered, the regular payments can provide valued stability to household incomes. Some schemes have also reported that payments can help ensure land-tenure security with respect to squatters by legitimizing the service provider's right to occupy the land and sell its services.

There are other less direct but perhaps no less important benefits. The conservation provided by PES schemes can also promote the opportunity for income from the sale of non-forest timber products. Improved conservation may also improve productivity though improving the state of other ecosystem services such as pollination and soil retention. Finally, the process of entering into and administering PES schemes can provide local training, technical assistance, improving community organization and social capital (Chomitz et al. 1999).

At the same time, there are potential harms to local communities that PES schemes may cause, as well. Most obvious, PES schemes may unintentionally create barriers to entry that exclude poor communities or land owners. If poor landowners have less secure title than wealthier landowners, they may not be able to participate. Uneven land distribution may mean that large land owners find it worthwhile to enroll in PES schemes because the transaction costs are relatively small for them. Many poor land owners with small holdings may, by contrast, find it does not make sense to go through all of the PES scheme costs given how little services their land may generate. Indeed transaction costs can be quite high, particularly for smallholders (Scherr and Bracer 2006). These include the costs of negotiation, entering into contractual obligations, monitoring compliance, and payments. A Forest Trends study found that (Forest Trends 2006):

In cases where buyers are physically and socially remote from sellers, a chain of intermediaries may be required for the transfer of funds. One preliminary assessment suggests that transaction costs in forest carbon projects (presently the most complex market) absorb more than 50 percent (and in some cases more than 90 percent) of the value of total payments made, while the forest producer directly receives only the residual. 
FONAFIFO's costs are 7\%, plus a top cost of $18 \%$ for the forest engineer, while some research in China suggests a figure of $65 \%$. The potential of PES to deliver new streams of income to rural communities depends crucially on reducing costs and risks throughout the 'value chain' for PES. Some pilot PES projects have found various ways to dramatically reduce these costs and risks:

Another group that needs to be considered is those users who may not own the land but still use it and could be harmed by land management practices required by PES contracts.

While it is important for PES designers to consider fully the equity impacts of their schemes, it is equally important to note that many of the negative consequences remain theoretical at this point. The specific harms that need to be considered will depend on the particular details and context of each scheme. 


\section{References}

Asquith, N. and Vargas, M.T. 2007. Fair deals for watershed services in Bolivia.

Natural Resource Issues No 7. IIED, London

Barbier, E.B., Acreman M.C. and Knowler, D. 1997. Economic Valuation of Wetlands: a Guide for Policy Makers and Planners, Ramsar Convention Bureau, Gland, Switzerland.

Chomitz, K., E. Brenes, and L. Constantino. 1999. Financing environmental services: The Costa Rican experience and its implications. In The Science of the Total Environment. pp. 157-169.

Costanza et al. 1997. The value of the world's ecosystem services and natural capital. Nature 387:253-260.

Daily, G.C. 1997. Nature's Services: Societal Dependence on Natural Ecosystems. Island Press, Washington.

Daily, G.C., T. Söderqvist, S. Aniyar, K. Arrow, P. Dasgupta, P.R. Ehrlich, C. Folke, A. Jansson, B. Jansson, N. Kautsky, S. Levin, J. Lubchenco, K. Mäler, D. Simpson, D. Starrett, D. Tilman, and B. Walker. 2000. The value of nature and the nature of value. Science 289: 395-396.

Daily, G.C. and K Ellison. 2002. The New Economy of Nature: The Quest to Make Conservation Profitable, Island Press, Washington, DC .

Echevarria, J. 2005. Regulating Versus Paying Land Owners to Protect the Environment, Journal of Land Resources \& Environmental Law 26:1.

Farrier, D. 1995. Conserving Biodiversity on Private Land: Incentives for Management or Compensation for Lost Expectations?, Harvard Environmental. Law Review 19:303.

Flournoy, A. and Robert Verchick. October 11, 2005. The Unnatural Disaster of Katrina. Center for American Progress. <http://www.americanprogress.org/issues/2005/10/b1102571.html>

Forest Stewardship Council. 2009. <http://www.fscus.org/>.

Forest Trends. 2006. Developing Future Ecosystem Service Payments in China: Lessons Learned from International Experience. Washington, D.C.

Heal, G., G. C. Daily, P. R. Ehrlich, J. Salzman, C. Boggs, J. Hellman, J. Hughes, C. Kremen, and T. Ricketts. 2001. Protecting natural capital through ecosystem service districts. Stanford Environmental Law Journal 20:333-364.

IUCN. 2006. Pay: Establishing Payments for Watershed Services. Gland, Switzerland.

IUCN. In publication. Legal issues in watershed payments for ecosystem services. Gland, Switzerland.

Jackson, RB, EG Jobbágy, R Avissar, S Baidya Roy, D Barrett, CW Cook, KA Farley, DC le Maitre, BA McCarl, BC Murray. 2005. Trading water for carbon with biological carbon sequestration. Science 310: 1944-1947. 
Landell-Mills, N. and I.T. Porras. 2002. Silver bullet or fools' gold? A global review of markets for forest environmental services and their impacts on the poor. International Institute for Environment and Development (IIED), London.

Markandya. 2006. EEM, Study on Payment for Ecological and Environmental Services in China, Fondaziona Eni Enrico Mattei. Milan, Italy.

Millennium Ecosystem Assessment (MEA). 2005. Ecosystems and Human Well-Being: Synthesis. Island Press, Washington.

Miranda, M., Porras, I.T., and Moreno, M.L. 2003. The Social Impacts of Payments for Environmental Services in Costa Rica : A Quantitative Field Survey and Analysis of the Virilla Watershed. IIED, London.

OECD. July 2009. Developments in Agri-environmental Policies in OECD Countries OECD Agriculture \& Food 6:66.

Pagiola, S., J. Bishop and N. Landell-Mills. 2002. Selling forest environmental services: Marketbased mechanisms for conservation and development. London, UK: Earthscan Publications.

Pagiola, S., A. Arcenas, and G. Platais. 2003. Ensuring that the poor benefit from payments for environmental services. Washington, D.C., U.S.A: World Bank.

Perrot-Maître, D. (2006) The Vittel payments for ecosystem services: a "perfect" PES case? International Institute for Environment and Development, London, UK.

PRESA. 2009. <http://presa.worldagroforestry.org/>

Rosa, H., S. Kandel, and L. Dimas. 2003. Compensation of environmental services for rural communities: Lessons from the Americas and key issues for strengthening community strategies. PRISMA. San Salvador, El Salvador.

Salzman, J. 1997. Valuing Ecosystem Services, 24 Ecology Law Quarterly 887 (1997)

Salzman, J. 1997a. The Use and Abuse of Environmental Labels. Journal of Industrial Ecology. $1: 11$.

Salzman, J. and J.B. Ruhl, 2001. Currencies and the Commodification of Environmental Law. Stanford Law Review 53:607.

Salzman J., 2005. Creating Markets for Ecosystem Services: Notes From the Field. NYU Law Review 80:870.

J. Salzman and Barton Thompson, Jr. 2007. Concepts and Insights in Environmental Law, $2^{\text {nd }}$ ed. Foundation Press. Eagan, Minnesota.

Scherr, S. and C. Bracer. 2006. Poverty reduction through payments for ecosystem services. Washington, DC: Forest Trends and Ecoagriculture Partners.

Stoneham G. et al.. 2002. Auctions for Conservation Contracts: An Empirical Examination of Victoria's BushTender Trial. <http://eprints.anu.edu.au/archive/00002198/01/stoneha1.pdf>. 
Wara, M. 2007. Is the Global Carbon Market Working? Nature 495:595 (8 February 2007).

Wunder, S. 2005. Payments for environmental services: some nuts and bolts. Occasional Paper no. 42, CIFOR, Indonesia.

USDA, Farm Service Agency. 2003. Conservation Reserve Program Fact Sheet. 